\title{
Rainy Season Cultivars and Hybrid Parents
}

\author{
P. Srinivasa Rao, C. Ganesh Kumar, Belum V. S. Reddy, \\ A. Kamal, H. C. Sharma and R. P. Thakur
}

\begin{abstract}
This chapter entitled "Rainy season cultivars and hybrid parents" gives a focussed description of improved sweet sorghum varieties/restorers, hybrids and female hybrid parents (as per PPVFRA). The coloured picture of the line is provided for easy identification. The genetic variability for all the metric traits is conspicuous and for some of the qualitative traits like anthocyanin coloration, glume color differences between the lines are not quite revealing. Among the biochemical traits such as sucrose, glucose and fructose the differences are significant among the cultivars.
\end{abstract}

Keywords Cultivars · Hybrids · Pedigree - Rainy • Kharif • Quantitative Traits • Brix\%, stalk yield, sugar yield, grain yield $\cdot$ Glucose $\cdot$ Fructose $\cdot$ Sucrose

P. Srinivasa Rao $(\varangle)$ - B. V. S. Reddy $~ H$ H. C. Sharma R. P. Thakur International Crops Research Institute for the Semi-Arid Tropics (ICRISAT),

Patancheru 502324, India

e-mail: psrao72@gmail.com

C. Ganesh Kumar · A. Kamal

Chemical Biology Laboratory, CSIR-Indian Institute of Chemical Technology (CSIR-IICT),

Uppal Road, Hyderabad 500607, India 


\section{ICSV 700 Salient Features}

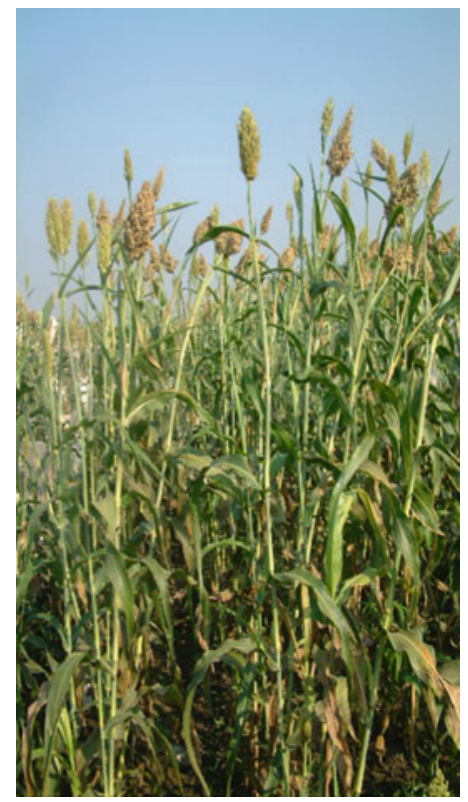

1. Pedigree: (IS $1082 \times$ SC 108-3)-1-1-1-1-1.

2. Days to $50 \%$ flowering: 84 days.

3. Plant height $(\mathrm{m}): 3.4$

4. Plant girth $(\mathrm{mm}): 17.6$

5. Biomass yield $\left(\mathrm{t} \mathrm{ha}^{-1}\right): 45.6$

6. Juice yield $\left(\mathrm{t} \mathrm{ha}^{-1}\right): 17.4$

7. Juice extraction (\%): 38

8. Brix (\%): 16

9. Sugar yield $\left(\mathrm{t} \mathrm{ha}^{-1}\right): 2.1$

10. Grain yield $\left(\mathrm{t} \mathrm{ha}^{-1}\right): 3.1$

11. Male fertility restoration $(\%): 85$

12. Sucrose (\%): 7.9

13. Glucose (\%): 0.7

14. Fructose (\%): 0.2

15. $\mathrm{pH}$ of juice: 5.0

16. Electrical conductivity of juice $\left(\mathrm{mS} \mathrm{m}^{-1}\right)$.

* Milli siemens per meter: 8.4

17. Tolerance to: Stem borer, Shootfly, Rust.

18. Adaptation: Rainy season. 
Traits recorded as per guidelines for sorghum as approved by PPVFRA ${ }^{\text {a }}$

Characteristics

Characteristic value of

Remarks

candidate variety

measured value

\begin{tabular}{llllllllll}
\hline 1 & 2 & 3 & 4 & 5 & 6 & 7 & 8 & 9 & etc.
\end{tabular}

Seedling: anthocyanin colouration of coleoptile

Leaf sheath: anthocyanin colouration

Leaf: midrib colour (5th fully developed leaf)

Plant: time of panicle emergence (50\% of the plants with complete panicle emergence)

Plant: natural height of foliage up to base of flag leaf

Flag leaf: yellow colouration of midrib

Lemma: arista formation (awns)

Stigma: anthocyanin coloration

Stigma: yellow coloration

Stigma length $(\mathrm{mm})$

Flower with pedicel: length of flower

Anther: length

Anther: colour of dry anther

Glume: color

Plant: total height

Stem: diameter (at lower one-third height of plant) $(\mathrm{mm})$

Leaf: length of blade of the third leaf from top including flag leaf $(\mathrm{cm})$

Leaf: width of blade of the third leaf from top including flag leaf $(\mathrm{cm})$

Panicle: length without peduncle

Panicle: length of branches (middle third of panicle)

Panicle: density at maturity (ear head compactness)

Panicle: shape

Neck of panicle: visible length above sheath (cm)

Glume coverage $(\%)$

Threshability

Caryopsis: colour after threshing

Grain: weight of 1000 grains (g)

Grain: shape in dorsal view

Grain: shape in profile view

Grain: size of mark of germ

Grain: texture of endosperm (in longitudinal section)

Grain: colour of vitreous albumen

Grain: lustre

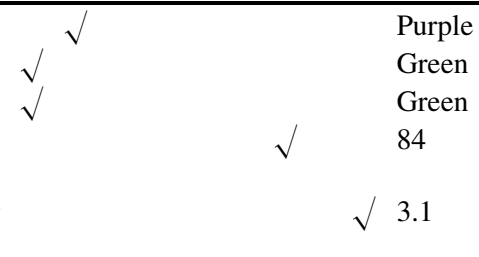

Absent

$\sqrt{ }$ Strong

Absent

Medium

$\sqrt{ }$ Long

Medium

Medium

Orange

Light red

$\sqrt{ } 3.4$

17.6

71.6

$\sqrt{ } 8.1$

18.6

6.1

Semi compact

Symmetric

3.8

50

Partly

threshable

White

28.0

Circular

Circular

$\sqrt{ } \quad$ Large

$\sqrt{ } \quad 25 \%$ corneous

${ }^{a}$ PPVFRA Protection of Plant Varieties and Farmers Rights Act

Yellow

Lustrous 


\section{ICSV 25272 Salient Features}

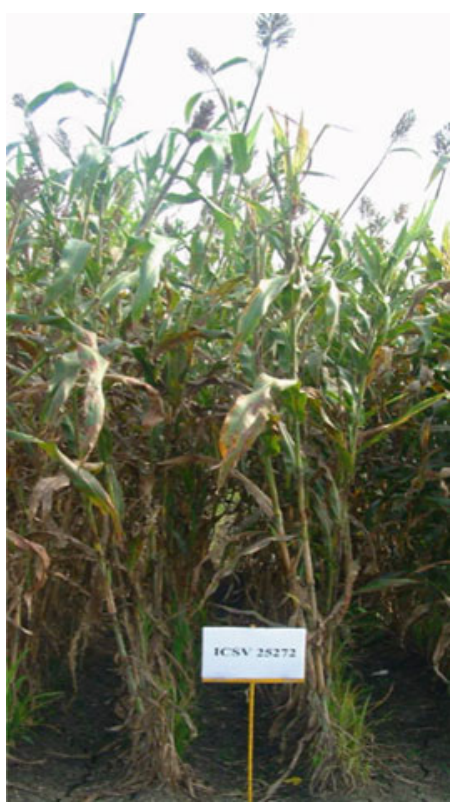

1. Pedigree: (DSV $4 \times$ SSV 84)-2-2-1-2

2. Days to $50 \%$ flowering: 74 days.

3. Plant height $(\mathrm{cm}): 3.1$

4. Plant girth (mm): 14.5

5. Biomass yield $\left(\mathrm{t} \mathrm{ha}^{-1}\right): 55.6$

6. Juice yield $\left(\mathrm{t} \mathrm{ha}^{-1}\right): 26.3$

7. Juice extraction (\%): 47

8. Brix $(\%) 17$

9. Sugar yield $\left(\mathrm{t} \mathrm{ha}^{-1}\right): 3.2$

10. Grain yield $\left(\mathrm{t} \mathrm{ha}^{-1}\right): 3.4$

11. Male fertility restoration (\%): 80

12. Sucrose (\%): 6.4

13. Glucose $(\%): 1.8$

14. Fructose (\%): 1.1

15. $\mathrm{pH}$ of Juice: 5.0

16. Electrical conductivity of Juice $\left(\mathrm{mS} \mathrm{m}^{-1}\right) *$ Milli siemens per meter: 9.5

17. Tolerance to: Aphids.

18. Adaptation: Rainy season. 
Traits recorded as per guidelines for sorghum as approved by PPVFRA ${ }^{\text {a }}$

Characteristics

Characteristic value of Remarks candidate variety

measured value

\begin{tabular}{llllllllll}
\hline 1 & 2 & 3 & 4 & 5 & 6 & 7 & 8 & 9 & etc.
\end{tabular}

Seedling: anthocyanin colouration of coleoptile

Leaf sheath: anthocyanin colouration

Leaf: midrib colour (5th fully developed leaf)

Plant: time of panicle emergence $(50 \%$ of the plants with complete panicle emergence)

Plant: natural height of foliage up to base of flag leaf

Flag leaf: yellow colouration of midrib

Lemma: arista formation (awns)

Stigma: anthocyanin coloration

Stigma: yellow coloration

Stigma length $(\mathrm{mm})$

Flower with pedicel: length of flower

Anther: length

Anther: colour of dry anther

Glume: color

Plant: total height

Stem: diameter (at lower one-third height of plant) (mm)

Leaf: length of blade of the third leaf from top including flag leaf $(\mathrm{cm})$

Leaf: width of blade of the third leaf from top including flag leaf $(\mathrm{cm})$

Panicle: length without peduncle

Panicle: length of branches (middle third of panicle)

Panicle: density at maturity (ear head compactness)

Panicle: shape

Neck of panicle: visible length above sheath $(\mathrm{cm})$

Glume coverage $(\%)$

Threshability

Caryopsis: colour after threshing

Grain: weight of 1000 grains (g)

Grain: shape in dorsal view

Grain: shape in profile view

Grain: size of mark of germ

Grain: texture of endosperm (in longitudinal section)

Grain: colour of vitreous albumen

Grain: lustre

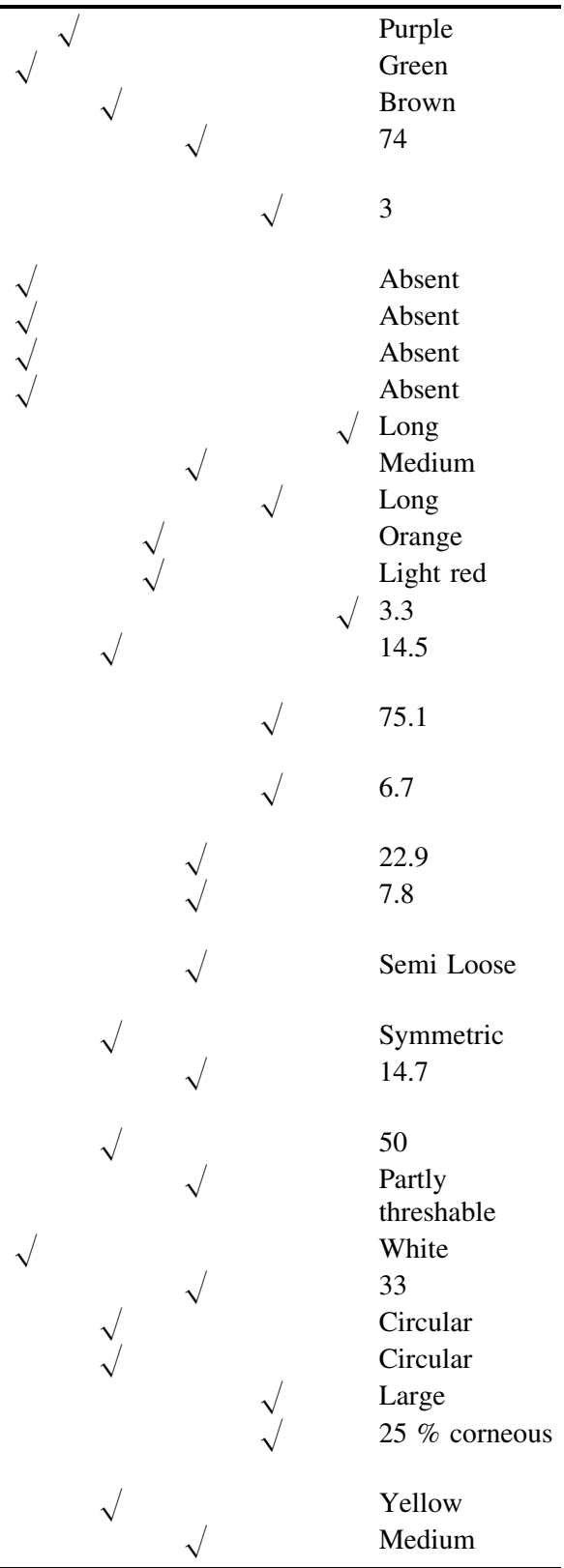

${ }^{a}$ PPVFRA Protection of Plant Varieties and Farmers Rights Act 


\section{ICSV 25274 Salient Features}

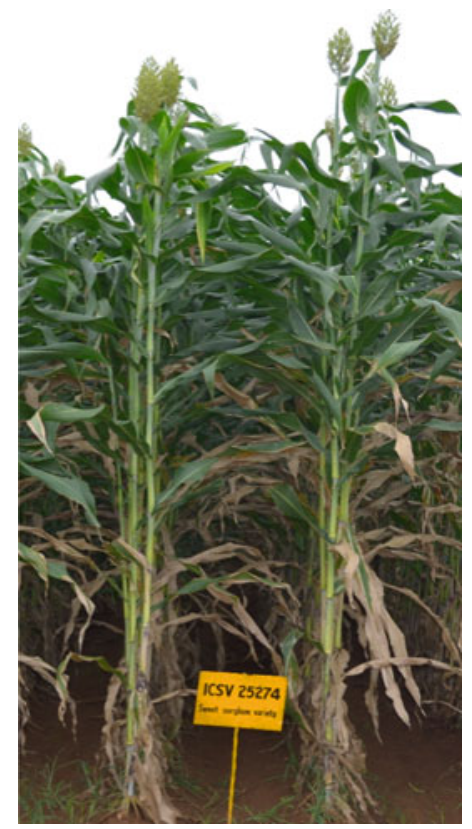

1. Pedigree: (DSV $4 \times$ SSV 84)-2-5-1-3

2. Days to $50 \%$ flowering: 87 days

3. Plant height $(\mathrm{m}): 3.5$

4. Plant girth (mm): 20.45

5. Biomass yield $\left(\mathrm{t} \mathrm{ha}^{-1}\right): 49.1$

6. Juice yield $\left(\mathrm{t} \mathrm{ha}^{-1}\right): 19.6$

7. Juice extraction (\%): 40

8. Brix (\%): 20

9. Sugar yield $\left(\mathrm{t} \mathrm{ha}^{-1}\right): 2.9$

10. Grain yield $\left(\mathrm{t} \mathrm{ha}^{-1}\right): 2.6$

11. Male fertility restoration $(\%): 85$

12. Sucrose (\%): 9.6

13. Glucose (\%): 2.0

14. Fructose (\%): 0.4

15. $\mathrm{pH}$ of Juice: 5.0

16. Electrical conductivity of Juice $\left(\mathrm{mS} \mathrm{m}^{-1}\right) *$ milli siemens per meter: 8.1

17. Tolerance to: Aphids, moderately resistant to Shoot fly and Grain mold.

18. Adaptation: Rainy season 
Traits recorded as per guidelines for sorghum as approved by PPVFRA ${ }^{\text {a }}$

Characteristics

Characteristic value of Remarks candidate variety

measured value

\begin{tabular}{lllllllll}
\hline 1 & 2 & 3 & 4 & 5 & 6 & 7 & 8 & 9
\end{tabular} etc.

Seedling: anthocyanin colouration of coleoptiles

Leaf sheath: anthocyanin colouration

Leaf: midrib colour (5th fully developed leaf)

Plant: time of panicle emergence $(50 \%$ of the plants with complete panicle emergence)

Plant: natural height of foliage up to base of flag leaf

Flag leaf: yellow colouration of midrib

Lemma: arista formation (awns)

Stigma: anthocyanin coloration

Stigma: yellow coloration

Stigma length (mm)

Flower with pedicel: length of flower

Anther: length

Anther: colour of dry anther

Glume: color

Plant: total height

Stem: diameter (at lower one-third height of plant) $(\mathrm{mm})$

Leaf: length of blade of the third leaf from top including flag leaf $(\mathrm{cm})$

Leaf: width of blade of the third leaf from top including flag leaf $(\mathrm{cm})$

Panicle: length without peduncle

Panicle: length of branches (middle third of panicle)

Panicle: density at maturity (ear head compactness)

Panicle: shape

Neck of panicle: visible length above sheath $(\mathrm{cm})$

Glume coverage (\%)

Threshability

Caryopsis: colour after threshing

Grain: weight of 1000 grains (g)

Grain: shape in dorsal view

Grain: shape in profile view

Grain: size of mark of germ

Grain: texture of endosperm (in longitudinal section)

Grain: colour of vitreous albumen

Grain: luster

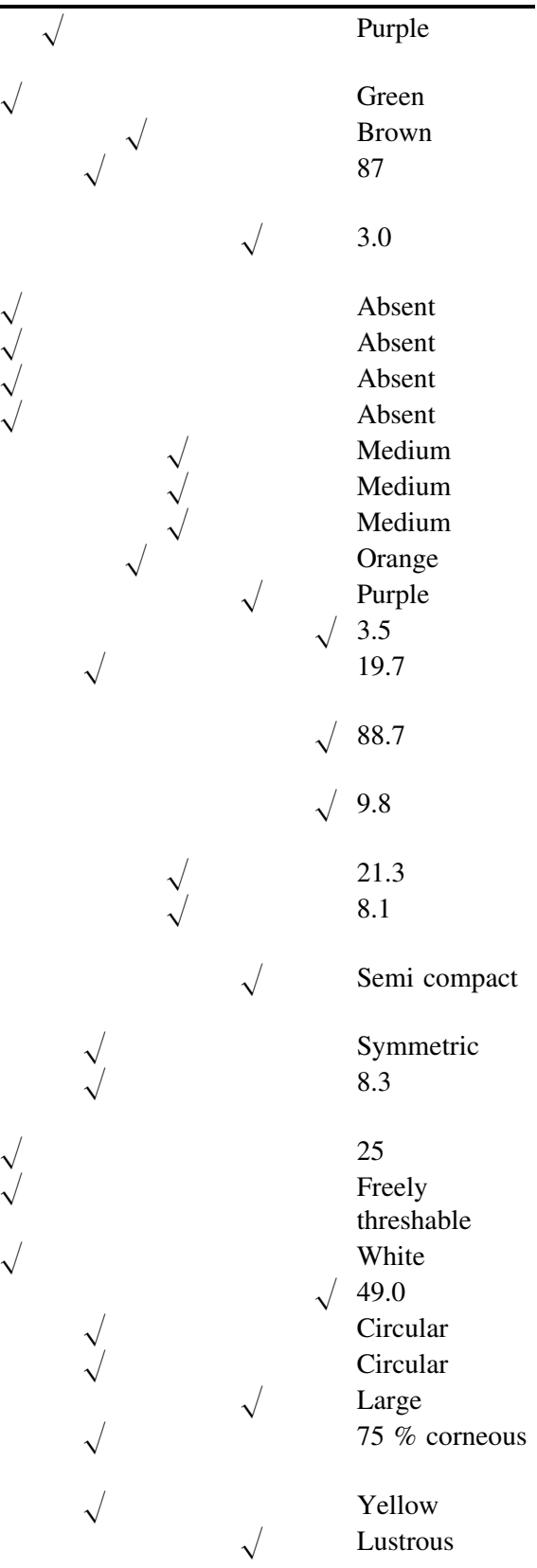

${ }^{\text {a PPVFRA Protection of Plant Varieties and Farmers Rights Act }}$ 


\section{ICSV 25275 Salient Features}

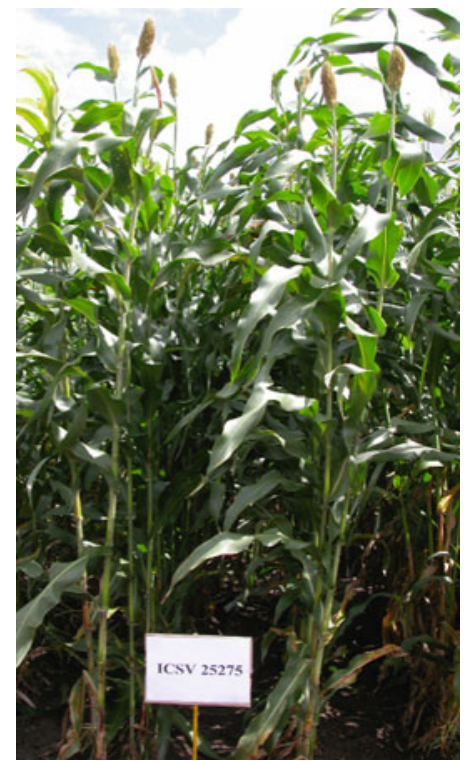

1. Pedigree: (IS $19587 \times$ B 24)-2-1-1-1

2. Days to $50 \%$ flowering: 81 days

3. Plant height $(\mathrm{m}): 3.3$

4. Plant girth $(\mathrm{mm}): 15.2$

5. Biomass yield $\left(\mathrm{t} \mathrm{ha}^{-1}\right): 46.6$

6. Juice yield $\left(\mathrm{t} \mathrm{ha}^{-1}\right): 11.8$

7. Juice extraction (\%): 23.5

8. Brix (\%): 16

9. Sugar yield $\left(\mathrm{t} \mathrm{ha}^{-1}\right): 2.8$

10. Grain yield $\left(\mathrm{t} \mathrm{ha}^{-1}\right): 2.7$

11. Male fertility restoration (\%): 85

12. Sucrose (\%): 7.7

13. Glucose (\%): 1.7

14. Fructose (\%): 0.4

15. $\mathrm{pH}$ of Juice: 5.0

16. Electrical conductivity of juice $\left(\mathrm{mS} \mathrm{m}^{-1}\right) *$ milli siemens per meter: 7.7

17. Tolerance to: Shootfly, Aphids, Rust.

18. Adaptation: Rainy season 
Traits recorded as per guidelines for sorghum as approved by PPVFRA ${ }^{\text {a }}$

Characteristics

Characteristic value of

Remarks

candidate variety

measured value

\begin{tabular}{llllllllll}
\hline 1 & 2 & 3 & 4 & 5 & 6 & 7 & 8 & 9 & etc.
\end{tabular}

Seedling: anthocyanin colouration of coleoptile

Leaf sheath: anthocyanin colouration

Leaf: midrib colour (5th fully developed leaf)

Plant: time of panicle emergence (50\% of the plants with complete panicle emergence)

Plant: natural height of foliage up to base of flag leaf

Flag leaf: yellow colouration of midrib

Lemma: arista formation (awns)

Stigma: anthocyanin coloration

Stigma: yellow coloration

Stigma length $(\mathrm{mm})$

Flower with pedicel: length of flower

Anther: length

Anther: colour of dry anther

Glume: color

Plant: total height

Stem: diameter (at lower one-third height of plant) (mm)

Leaf: length of blade of the third leaf from top including flag leaf $(\mathrm{cm})$

Leaf: width of blade of the third leaf from top including flag leaf $(\mathrm{cm})$

Panicle: length without peduncle

Panicle: length of branches (middle third of panicle)

Panicle: density at maturity (ear head compactness)

Panicle: shape

Neck of panicle: visible length above sheath $(\mathrm{cm})$

Glume coverage $(\%)$

Threshability

Caryopsis: colour after threshing

Grain: weight of 1000 grains (g)

Grain: shape in dorsal view

Grain: shape in profile view

Grain: size of mark of germ

Grain: texture of endosperm (in longitudinal section)

Grain: colour of vitreous albumen

Grain: lustre

Purple

Purple

Brown

81 days

2.8

Absent

Strong

Absent

Absent

Medium

Medium

Medium

Dark orange

Red

15.2

72.7

7.9

17.1

5.4

Semi compact

Symmetric

6.7

50

Partly

threshable

White

30.0

Circular

Circular

Large

$25 \%$ corneous

Yellow

Medium

${ }^{a}$ PPVFRA Protection of Plant Varieties and Farmers Rights Act 


\section{ICSV 25280 Salient Features}

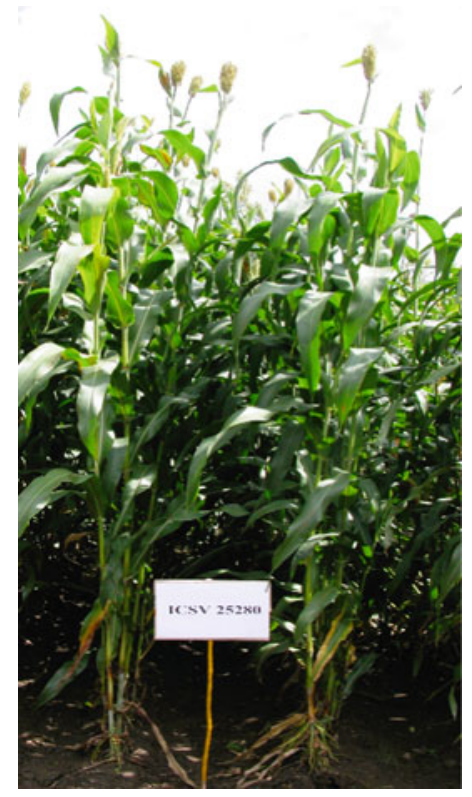

1. Pedigree: (ICSV $93046 \times$ SSV 84)-7-2-1-3

2. Days to $50 \%$ flowering: 83 days

3. Plant height $(\mathrm{m}): 3.3$

4. Plant girth (mm): 15.1

5. Biomass yield $\left(\mathrm{t} \mathrm{ha}^{-1}\right): 45.4$

6. Juice yield $\left(\mathrm{t} \mathrm{ha}^{-1}\right): 24.4$

7. Juice extraction (\%): 54

8. Brix (\%): 19

9. Sugar yield $\left(\mathrm{t} \mathrm{ha}^{-1}\right): 3.1$

10. Grain yield $\left(\mathrm{t} \mathrm{ha}^{-1}\right): 2.4$

11. Male fertility restoration (\%): 90

12. Sucrose (\%): 8.9

13. Glucose (\%): 1.9

14. Fructose (\%): 0.4

15. $\mathrm{pH}$ of juice: 5.0

16. Electrical conductivity of juice $\left(\mathrm{mS} \mathrm{m}^{-1}\right) *$ milli siemens per meter: 7.6

17. Tolerance to: Aphids, Shootfly, Stem borer.

18. Adaptation: Rainy season. 
Traits recorded as per guidelines for sorghum as approved by PPVFRA ${ }^{\text {a }}$

Characteristics

Characteristic value of

Remarks

candidate variety

measured value

\begin{tabular}{llllllllll}
\hline 1 & 2 & 3 & 4 & 5 & 6 & 7 & 8 & 9 & etc.
\end{tabular}

Seedling: anthocyanin colouration of coleoptile

Leaf sheath: anthocyanin colouration

Leaf: midrib colour (5th fully developed leaf)

Plant: time of panicle emergence (50\% of the plants with complete panicle emergence)

Plant: natural height of foliage up to base of flag leaf

Flag leaf: yellow colouration of midrib

Lemma: arista formation (awns)

Stigma: anthocyanin coloration

Stigma: yellow coloration

Stigma length (mm)

Flower with pedicel: length of flower

Anther: length

Anther: colour of dry anther

Glume: color

Plant: total height

Stem: diameter (at lower one-third height of plant) $(\mathrm{mm})$

Leaf: length of blade of the third leaf from top including flag leaf $(\mathrm{cm})$

Leaf: width of blade of the third leaf from top including flag leaf $(\mathrm{cm})$

Panicle: length without peduncle

Panicle: length of branches (middle third of panicle)

Panicle: density at maturity (ear head compactness)

Panicle: shape

Neck of panicle: visible length above sheath (cm)

Glume coverage (\%)

Threshability

Caryopsis: colour after threshing

Grain: weight of 1000 grains (g)

Grain: shape in dorsal view

Grain: shape in profile view

Grain: size of mark of germ

Grain: texture of endosperm (in longitudinal section)

Grain: colour of vitreous albumen

Grain: lustre

Purple

Purple

Green

83 days

2.7

Absent

Strong

Absent

Medium

Medium

Medium

Medium

Dark orange

Purple

3.3

15.1

72.4

$\sqrt{ } 8.5$

16.8

6.1

Semi compact

Symmetric

6.5

50

Partly

threshable

White

34.0

Circular

Circular

Large

$75 \%$ corneous

Yellow

Lustrous

${ }^{a}$ PPVFRA Protection of Plant Varieties and Farmers Rights Act 


\section{ICSV 93046 Salient Features}

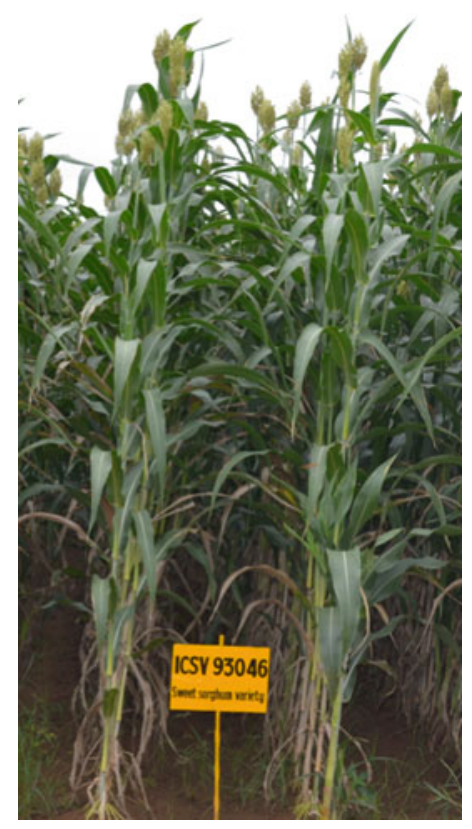

1. Pedigree: [((IS $1082 \times$ SC 108 -3)-1-1-1-1-1) $\times((($ IS $5622 \times$ CS 3541)-201-1-1-1-1-1 $\times(\mathrm{UChV} 2 \times$ Bulk Y-55)-1-5-1)]-9-3-1-1-1

2. Days to $50 \%$ flowering: 86 days

3. Plant height $(\mathrm{m}): 3.6$

4. Plant girth $(\mathrm{mm}): 17.9$

5. Biomass yield $\left(\mathrm{t} \mathrm{ha}^{-1}\right): 54.0$

6. Juice yield $\left(\mathrm{t} \mathrm{ha}^{-1}\right): 25.6$

7. Juice extraction (\%): 47

8. Brix (\%): 19

9. Sugar yield $\left(\mathrm{t} \mathrm{ha}^{-1}\right): 3.1$

10. Grain yield $\left(\mathrm{t} \mathrm{ha}^{-1}\right): 2.7$

11. Male fertility restoration (\%): 90

12. Sucrose (\%): 9.0

13. Glucose $(\%): 1.6$

14. Fructose (\%): 0.2

15. $\mathrm{pH}$ of Juice: 5.0

16. Electrical conductivity of juice $\left(\mathrm{mS} \mathrm{m}^{-1}\right) *$ Milli siemens per meter: 8.9

17. Tolerance to: Shootfly, Anthracnose, Grain mold and Downy mildew.

18. Adaptation: Rainy season/Post rainy season. 
Traits recorded as per guidelines for sorghum as approved by PPVFRA ${ }^{\text {a }}$

Characteristics

Characteristic value of Remarks

candidate variety

Measured value

\begin{tabular}{lllllllll}
\hline 1 & 2 & 3 & 4 & 5 & 6 & 7 & 8 & 9
\end{tabular} etc.

Seedling: anthocyanin colouration of coleoptile

Leaf sheath: anthocyanin colouration

Leaf: midrib colour (5th fully developed leaf)

Plant: time of panicle emergence $(50 \%$ of the plants with complete panicle emergence)

Plant: natural height of foliage up to base of flag leaf

Flag leaf: yellow colouration of midrib

Lemma: arista formation (awns)

Stigma: anthocyanin coloration

Stigma: yellow coloration

Stigma length $(\mathrm{mm})$

Flower with pedicel: length of flower

Anther: length

Anther: colour of dry anther

Glume: color

Plant: total height

Stem: diameter (at lower one-third height of plant) (mm)

Leaf: length of blade of the third leaf from top including flag leaf $(\mathrm{cm})$

Leaf: width of blade of the third leaf from top including flag leaf $(\mathrm{cm})$

Panicle: length without peduncle

Panicle: length of branches (middle third of panicle)

Panicle: density at maturity (ear head compactness)

Panicle: shape

Neck of panicle: visible length above sheath $(\mathrm{cm})$

Glume coverage $(\%)$

Threshability

Caryopsis: colour after threshing

Grain: weight of 1000 grains (g)

Grain: shape in dorsal view

Grain: shape in profile view

Grain: size of mark of germ

Grain: texture of endosperm (in longitudinal section)

Grain: colour of vitreous albumen

Grain: luster

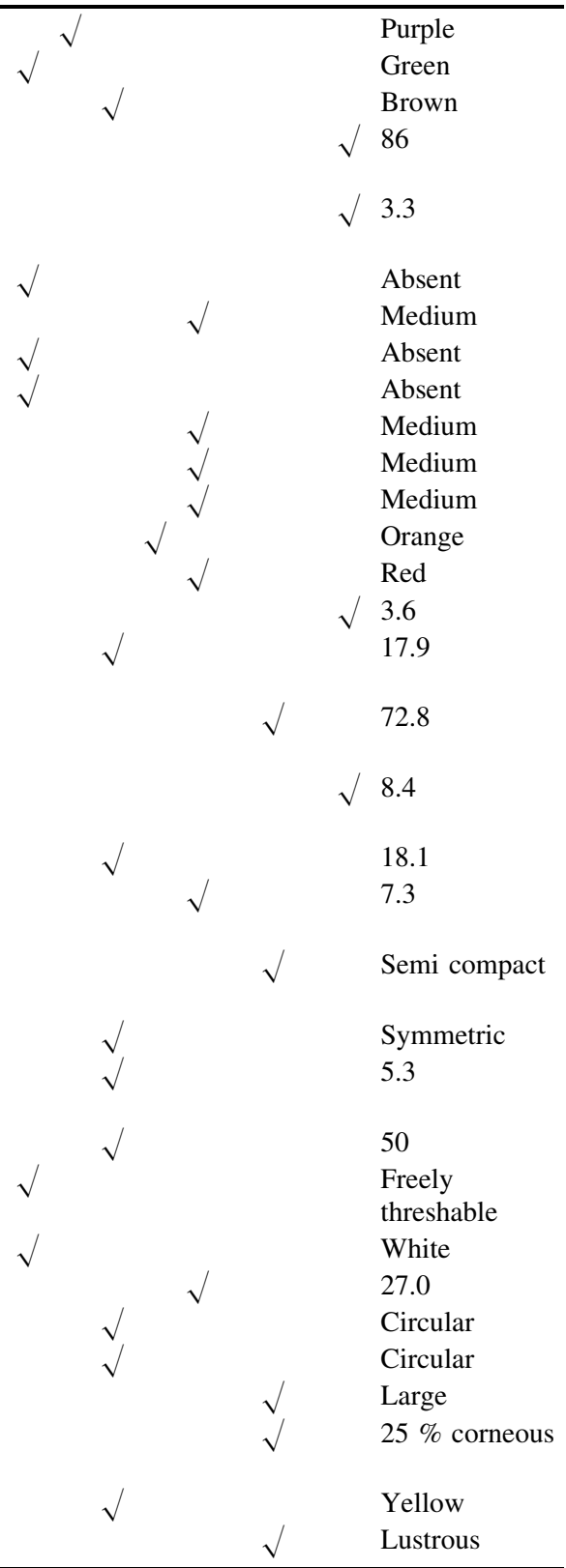

${ }^{a}$ PPVFRA Protection of Plant Varieties and Farmers Rights Act 


\section{SPV 422 Salient Features}

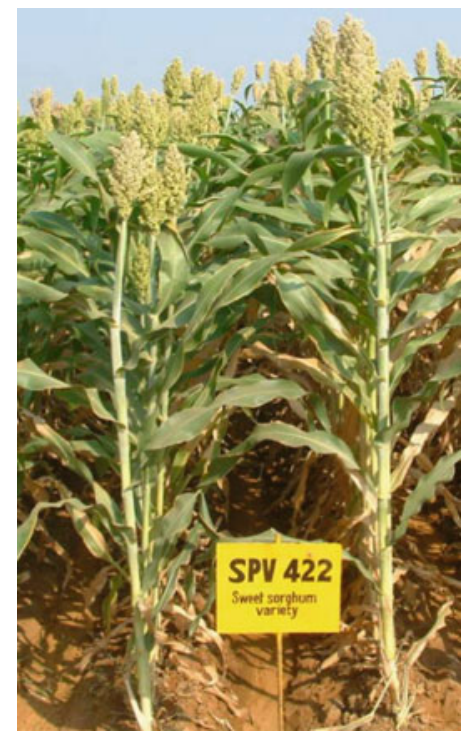

1. Pedigree: Good grain 1485 (ICSV 574/ICSR 165)

2. Days to $50 \%$ flowering: 86 days.

3. Plant height $(\mathrm{m}): 3.1$

4. Plant girth $(\mathrm{mm}): 21.6$

5. Biomass yield $\left(\mathrm{t} \mathrm{ha}^{-1}\right): 47.6$

6. Juice yield $\left(\mathrm{t} \mathrm{ha}^{-1}\right): 18.7$

7. Juice extraction (\%): 39

8. Brix (\%): 20

9. Sugar yield $\left(\mathrm{t} \mathrm{ha}^{-1}\right): 2.8$

10. Grain yield $\left(\mathrm{t} \mathrm{ha}^{-1}\right): 3.1$

11. Male fertility restoration $(\%): 85$

12. Sucrose (\%): 9.6

13. Glucose (\%): 2.6

14. Fructose (\%): 0.2

15. $\mathrm{pH}$ of juice $: 5.0$

16. Electrical conductivity of juice $\left(\mathrm{mS} \mathrm{m}^{-1}\right)^{*}$ milli siemens per meter: 8.8

17. Tolerance to: Anthracnose, Leaf blight.

18. Adaptation: Rainy season 
Traits recorded as per guidelines for sorghum as approved by PPVFRA ${ }^{\text {a }}$

Characteristics

Characteristic value of Remarks

candidate variety

Measured value

\begin{tabular}{llllllllll}
\hline 1 & 2 & 3 & 4 & 5 & 6 & 7 & 8 & 9 & etc.
\end{tabular}

Seedling: anthocyanin colouration of coleoptile

Leaf sheath: anthocyanin colouration

Leaf: midrib colour (5th fully developed leaf)

Plant: time of panicle emergence $(50 \%$ of the plants with complete panicle emergence)

Plant: natural height of foliage up to base of flag leaf

Flag leaf: yellow colouration of midrib

Lemma: arista formation (awns)

Stigma: anthocyanin coloration

Stigma: yellow coloration

Stigma length $(\mathrm{mm})$

Flower with pedicel: length of flower

Anther: length

Anther: colour of dry anther

Glume: color

Plant: total height

Stem: diameter (at lower one-third height of plant) (mm)

Leaf: length of blade of the third leaf from top including flag leaf $(\mathrm{cm})$

Leaf: width of blade of the third leaf from top including flag leaf $(\mathrm{cm})$

Panicle: length without peduncle

Panicle: length of branches (middle third of panicle)

Panicle: density at maturity (ear head compactness)

Panicle: shape

Neck of panicle: visible length above sheath $(\mathrm{cm})$

Glume coverage $(\%)$

Threshability

Caryopsis: colour after threshing

Grain: weight of 1000 grains (g)

Grain: shape in dorsal view

Grain: shape in profile view

Grain: size of mark of germ

Grain: texture of endosperm (in longitudinal section)

Grain: colour of vitreous albumen

Grain: lustre

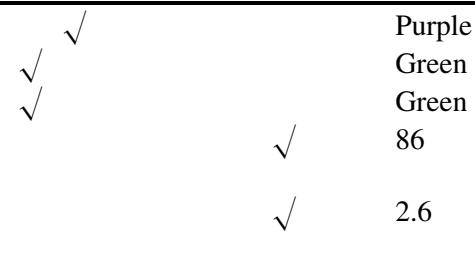

Purple

Green

Green

2.6

$\sqrt{ }$
$\sqrt{ }$
$\sqrt{ }$
$\sqrt{ }$

Absent

Absent

Absent

Absent

Short

Medium

Medium

Orange

Purple

$\sqrt{ } 3.1$

21.6

85.2

7.4

16.8

6.2

Semi compact

Symmetric

4.3

25

Partly

threshable

White

35.0

Circular

Circular

Large

$75 \%$ corneous

Yellow

Lustrous

${ }^{a}$ PPVFRA Protection of Plant Varieties and Farmers Rights Act 


\section{SSV 74 Salient Features}

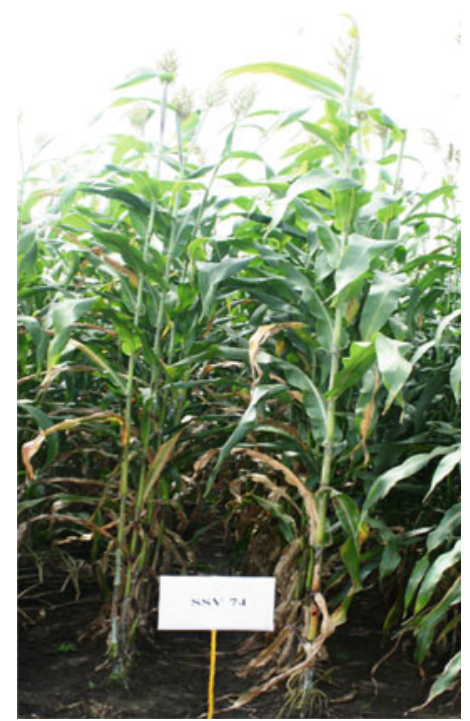

1. Pedigree: Selection from PAB 74 (Sudan; Bred by UAS, Dharwad)

2. Days to $50 \%$ flowering: 84 days

3. Plant height (m): 3.3

4. Plant girth (mm): 20.66

5. Biomass yield $\left(\mathrm{t} \mathrm{ha}^{-1}\right): 41.5$

6. Juice yield $\left(\mathrm{t} \mathrm{ha}^{-1}\right): 14.9$

7. Juice extraction (\%): 36

8. Brix (\%): 16

9. Sugar yield $\left(\mathrm{t} \mathrm{ha}^{-1}\right): 1.8$

10. Grain yield $\left(\mathrm{t} \mathrm{ha}^{-1}\right): 1.5$

11. Male fertility restoration (\%): 90

12. Sucrose (\%): 7.0

13. Glucose $(\%): 1.5$

14. Fructose (\%): 0.3

15. $\mathrm{pH}$ of juice: 5.0

16. Electrical conductivity of juice $\left(\mathrm{mS} \mathrm{m}^{-1}\right) *$ milli siemens per meter: 7.8

17. Tolerance to: Aphids, Rust.

18. Adaptation: Rainy season 
Traits recorded as per guidelines for sorghum as approved by PPVFRA ${ }^{\text {a }}$

Characteristics

Characteristic value of

Remarks

candidate variety

measured value

\begin{tabular}{lllllllll}
\hline 1 & 2 & 3 & 4 & 5 & 6 & 7 & 8 & 9
\end{tabular} etc.

Seedling: anthocyanin colouration of coleoptile

Leaf sheath: anthocyanin colouration

Leaf: midrib colour (5th fully developed leaf)

Plant: time of panicle emergence (50\% of the plants with complete panicle emergence)

Plant: natural height of foliage up to base of flag leaf

Flag leaf: yellow colouration of midrib

Lemma: arista formation (awns)

Stigma: anthocyanin coloration

Stigma: yellow coloration

Stigma length $(\mathrm{mm})$

Flower with pedicel: length of flower

Anther: length

Anther: colour of dry anther

Glume: color

Plant: total height

Stem: diameter (at lower one-third height of plant) (mm)

Leaf: length of blade of the third leaf from top including flag leaf $(\mathrm{cm})$

Leaf: width of blade of the third leaf from top including flag leaf $(\mathrm{cm})$

Panicle: length without peduncle

Panicle: length of branches (middle third of panicle)

Panicle: density at maturity (ear head compactness)

Panicle: shape

Neck of panicle: visible length above sheath (cm)

Glume coverage (\%)

Threshability

Caryopsis: colour after threshing

Grain: weight of 1000 grains (g)

Grain: shape in dorsal view

Grain: shape in profile view

Grain: size of mark of germ

Grain: texture of endosperm (in longitudinal section)

Grain: colour of vitreous albumen

Grain: lustre

Grayed purple

Grayed purple

Yellow green

84

3.0

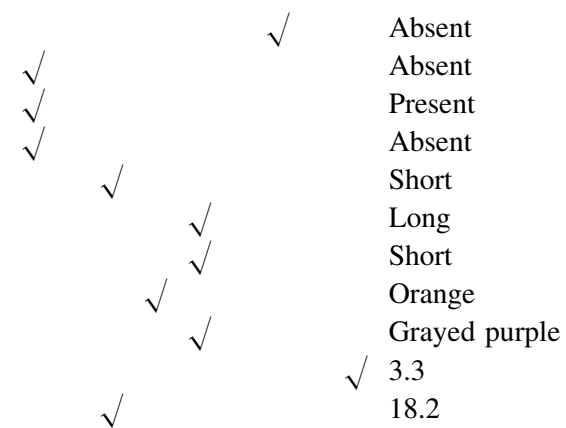

Absent

Absent

Present

Absent

Short

Long

Orange

Grayed purple

18.2

Medium

$\sqrt{ }$ Very broad

Medium

Medium

Semi loose

Panicle Broader

at Upper part

Very short

Short

Partly

threshable

White

36.0

Elliptic

Elliptic

Large

$25 \%$ corneous

Grayed yellow

Non lustrous

${ }^{a}$ PPVFRA Protection of Plant Varieties and Farmers Rights Act 


\section{SSV 84 Salient Features}

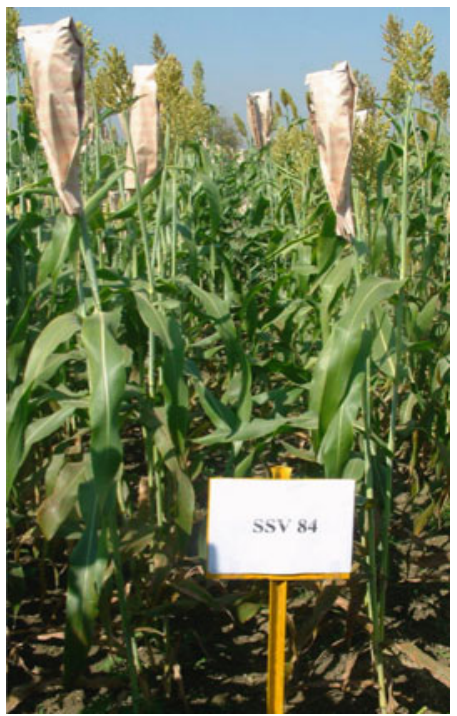

1. Pedigree: Selection from IS 23568 (Bred by MPKV, Rahuri)

2. Days to $50 \%$ flowering: 87 days

3. Plant height $(\mathrm{m}): 3.2$

4. Plant girth (mm): 18.3

5. Biomass yield $\left(\mathrm{t} \mathrm{ha}^{-1}\right): 38.7$

6. Juice yield $\left(\mathrm{t} \mathrm{ha}^{-1}\right): 13.5$

7. Juice extraction (\%): 35

8. Brix $(\%): 19$

9. Sugar yield $\left(\mathrm{t} \mathrm{ha}^{-1}\right): 1.9$

10. Grain yield $\left(\mathrm{t} \mathrm{ha}^{-1}\right): 3.3$

11. Male fertility restoration (\%): 90

12. Sucrose (\%): 8.8

13. Glucose (\%): 1.7

14. Fructose (\%): 0.4

15. $\mathrm{pH}$ of juice: 5.0

16. Electrical conductivity of juice $\left(\mathrm{mS} \mathrm{m}^{-1}\right) *$ milli siemens per meter:: 7.1

17. Tolerance to: Shootfly, Aphids, Rust.

18. Adaptation: Rainy season 
Traits recorded as per guidelines for sorghum as approved by PPVFRA ${ }^{\text {a }}$

Characteristics

Seedling: anthocyanin colouration of coleoptile

Leaf sheath: anthocyanin colouration

Leaf: midrib colour (5th fully developed leaf)

Plant: time of panicle emergence $(50 \%$ of the plants with complete panicle emergence)

Plant: natural height of foliage up to base of flag leaf

Flag leaf: yellow colouration of midrib

Lemma: arista formation (awns)

Stigma: anthocyanin coloration

Stigma: yellow coloration

Stigma length $(\mathrm{mm})$

Flower with pedicel: length of flower

Anther: length

Anther: colour of dry anther

Glume: color

Plant: total height

Stem: diameter (at lower one-third height of plant) (mm)

Leaf: length of blade of the third leaf from top including flag leaf $(\mathrm{cm})$

Leaf: width of blade of the third leaf from top including flag leaf $(\mathrm{cm})$

Panicle: length without peduncle

Panicle: length of branches (middle third of panicle)

Panicle: density at maturity (ear head compactness)

Panicle: shape

Neck of panicle: visible length above sheath (cm)

Glume coverage (\%)

Threshability

Caryopsis: colour after threshing

Grain: weight of 1000 grains (g)

Grain: shape in dorsal view

Grain: shape in profile view

Grain: size of mark of germ

Grain: texture of endosperm (in longitudinal section)

Grain: colour of vitreous albumen

Grain: lustre
Characteristic value of candidate variety

\begin{tabular}{lllllllll}
\hline 1 & 2 & 3 & 4 & 5 & 6 & 7 & 8 & 9
\end{tabular}
Remarks

Measured value

etc.

Yellow green

Yellow green

Yellow green

$\sqrt{ } 87$

$\sqrt{ } 2.9$

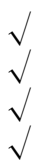

Absent

Absent

Present

Present

Medium

Long

Short

Grayed orange

Grayed purple

$\sqrt{ } 3.2$

18.3

$\sqrt{ }$ Long

$\sqrt{ }$ Very broad

Short

Medium

Semi compact

Panicle Braoder at Upper part

Absent

Short

Partly

threshable

Yellow White

25.0

Circular

Circular

Large

$25 \%$ corneous

Grayed yellow

Non lustrous

${ }^{\text {a PPVFRA Protection of Plant Varieties and Farmers Rights Act }}$ 


\section{RSSV 9 (CSV 19SS) Salient Features}

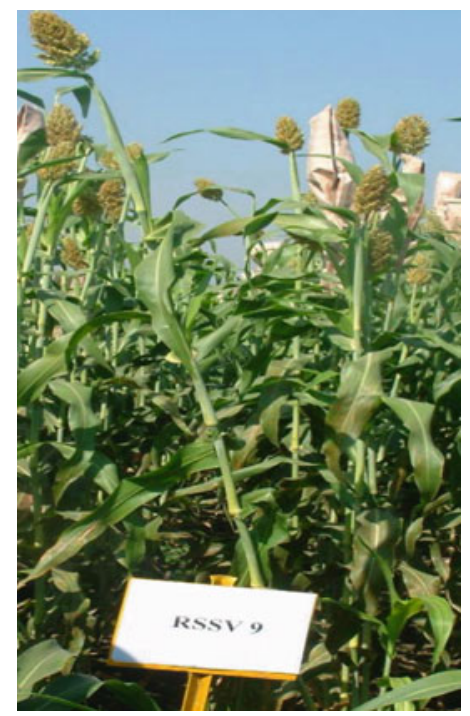

1. Pedigree: (RSSV 2 X SPV 462)-2-1-1 (Bred by MPKV, Rahuri)

2. Days to $50 \%$ flowering: 85 days

3. Plant height $(\mathrm{m}): 3.3$

4. Plant girth $(\mathrm{mm}): 17.8$

5. Biomass yield $\left(\mathrm{t} \mathrm{ha}^{-1}\right): 58.9$

6. Juice yield $\left(\mathrm{t} \mathrm{ha}^{-1}\right): 21.4$

7. Juice extraction (\%): 36

8. Brix $(\%): 16$

9. Sugar yield $\left(\mathrm{t} \mathrm{ha}^{-1}\right): 2.6$

10. Grain yield $\left(\mathrm{t} \mathrm{ha}^{-1}\right): 1.5$

11. Male fertility restoration $(\%): 90$

12. Sucrose (\%): 9.0

13. Glucose (\%): 1.7

14. Fructose (\%): 2.8

15. $\mathrm{pH}$ of Juice: 4.0

16. Electrical conductivity of juice $\left(\mathrm{mS} \mathrm{m}^{-1}\right) *$ milli siemens per meter: 9.4

17. Tolerance to: Aphids, Shootfly.

18. Adaptation: Rainy season 
Traits recorded as per guidelines for sorghum as approved by PPVFRA ${ }^{\text {a }}$

Characteristics

Characteristic value of Remarks candidate variety

measured value

\begin{tabular}{lllllllll}
\hline 1 & 2 & 3 & 4 & 5 & 6 & 7 & 8 & 9
\end{tabular} etc.

Seedling: anthocyanin colouration of coleoptile

Leaf sheath: anthocyanin colouration

Leaf: midrib colour (5th fully developed leaf)

Plant: time of panicle emergence $(50 \%$ of the plants with complete panicle emergence)

Plant: natural height of foliage up to base of flag leaf

Flag leaf: yellow colouration of midrib

Lemma: arista formation (awns)

Stigma: anthocyanin coloration

Stigma: yellow coloration

Stigma length (mm)

Flower with pedicel: length of flower

Anther: length

Anther: colour of dry anther

Glume: color

Plant: total height

Stem: diameter (at lower one-third height of plant) (mm)

Leaf: length of blade of the third leaf from top including flag leaf $(\mathrm{cm})$

Leaf: width of blade of the third leaf from top including flag leaf $(\mathrm{cm})$

Panicle: length without peduncle

Panicle: length of branches (middle third of panicle)

Panicle: density at maturity (ear head compactness)

Panicle: shape

$\begin{array}{lll}\sqrt{ } \sqrt{ } & & \text { Grayed purple } \\ \sqrt{ } & & \text { Grayed purple } \\ & & \text { Yellow green } \\ & & 85 \\ & & \sqrt{ } 2.9\end{array}$

Absent

$\checkmark$ Present

Present

Present

$\sqrt{ }$ Long

Long

Medium

Grayed orange

Grayed purple

$\sqrt{ } 3.3$

17.8

Neck of panicle: visible length above sheath $(\mathrm{cm})$

Glume coverage (\%)

Threshability

Caryopsis: colour after threshing

Grain: weight of 1000 grains (g)

Grain: shape in dorsal view

Grain: shape in profile view

Grain: size of mark of germ

Grain: texture of endosperm (in longitudinal section)

Grain: colour of vitreous albumen

Grain: lustre

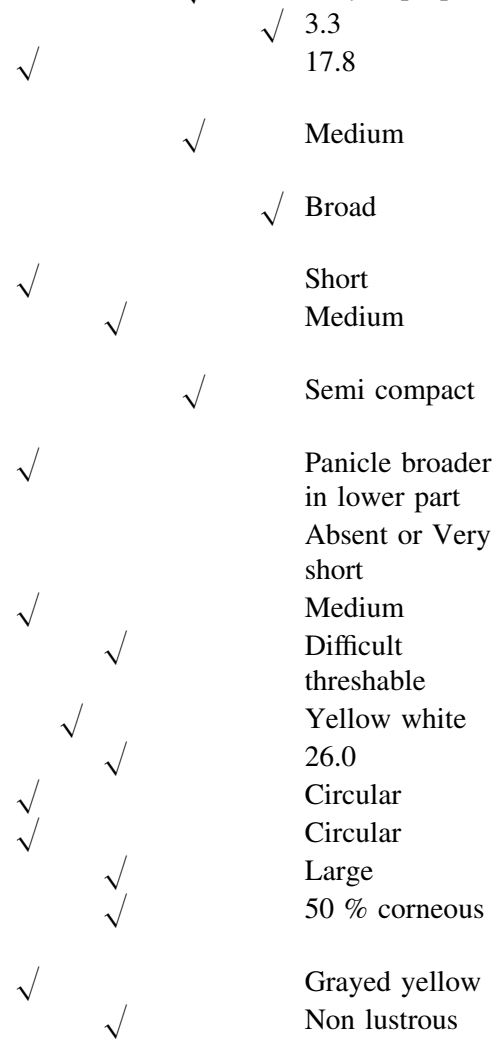

${ }^{\mathrm{a}}$ PPVFRA Protection of Plant Varieties and Farmers Rights Act 


\section{ICSB 38 Salient Features}

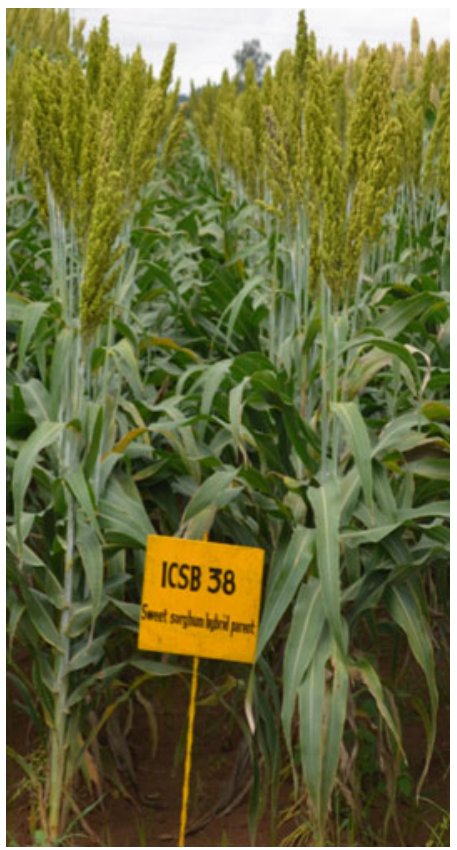

1. Pedigree: [(BTx $623 \times$ MR 862)B lines bulk]-5-1-3-5

2. Days to $50 \%$ flowering: 74 days

3. Plant height $(\mathrm{m}): 1.4$

4. Plant girth $(\mathrm{mm}): 17.7$

5. Biomass yield $\left(\mathrm{t} \mathrm{ha}^{-1}\right): 16.0$

6. Juice yield $\left(\mathrm{t} \mathrm{ha}^{-1}\right): 4.4$

7. Juice extraction (\%): 27.5

8. Brix $(\%)$ : 9

9. Sugar yield $\left(\mathrm{t} \mathrm{ha}^{-1}\right): 0.3$

10. Grain yield $\left(\mathrm{t} \mathrm{ha}^{-1}\right): 2.3$

11. Male fertility restoration (\%): 80

12. Sucrose (\%): 4.7

13. Glucose $(\%): 2.1$

14. Fructose (\%): 0.7

15. $\mathrm{pH}$ of juice: 5.5

16. Electrical conductivity of juice $\left(\mathrm{mS} \mathrm{m}^{-1}\right) *$ Milli siemens per meter: 14.7

17. Tolerance to: Shoot fly, Stem borer, Rust.

18. Adaptation: Rainy season. 
Traits recorded as per guidelines for sorghum as approved by PPVFRA ${ }^{\text {a }}$

Characteristics

Characteristic value of

Remarks

candidate hybrid parent

measured value

$\begin{array}{llllllllll}1 & 2 & 3 & 4 & 5 & 6 & 7 & 8 & 9\end{array}$ etc.

Seedling: anthocyanin colouration of coleoptile

Leaf sheath: anthocyanin colouration

Leaf: midrib colour (5th fully developed leaf)

Plant: time of panicle emergence $(50 \%$ of the plants with complete panicle emergence)

Plant: natural height of foliage up to base of flag leaf

Flag leaf: yellow colouration of midrib

Lemma: arista formation (awns)

Stigma: anthocyanin coloration

Stigma: yellow coloration

Stigma length $(\mathrm{mm})$

Flower with pedicel: length of flower

Anther: length

Anther: colour of dry anther

Glume: color

Plant: total height

Stem: diameter (at lower one-third height of plant) $(\mathrm{mm})$

Leaf: length of blade of the third leaf from top including flag leaf $(\mathrm{cm})$

Leaf: width of blade of the third leaf from top including flag leaf $(\mathrm{cm})$

Panicle: length without peduncle

Panicle: length of branches (middle third of panicle)

Panicle: density at maturity (ear head compactness)

Panicle: shape

Neck of panicle: visible length above sheath (cm)

Glume coverage $(\%)$

Threshability

Caryopsis: colour after threshing

Grain: weight of 1000 grains (g)

Grain: shape in dorsal view

Grain: shape in profile view

Grain: size of mark of germ

Grain: texture of endosperm (in longitudinal section)

Grain: colour of vitreous albumen

Grain: lustre

Green

Green

Brown

74

1.1

Absent

Absent

Absent

Average

Short

Short

Short

Orange

Light red

1.4

17.7

80.6

7.6

30.7

7.7

Semi compact

Symmetric

$\sqrt{ } 24$

25

Partly

threshable

White

26.0

Circular

Circular

Large

$75 \%$ corneous

Yellow

Non-lustrous

${ }^{a}$ PPVFRA Protection of Plant Varieties and Farmers Rights Act 


\section{ICSB 474 Salient Features}

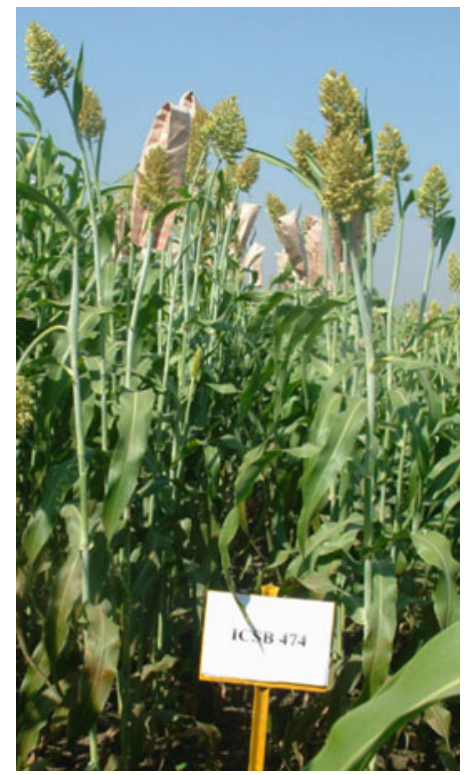

1. Pedigree: (IS $18432 \times$ ICSB 6)-11-1-1-2-2

2. Days to $50 \%$ flowering: 70 days

3. Plant height $(\mathrm{m}): 2.1$

4. Plant girth (mm): 14.1

5. Biomass yield $\left(\mathrm{t} \mathrm{ha}^{-1}\right): 23.1$

6. Juice yield $\left(\mathrm{t} \mathrm{ha}^{-1}\right): 8.0$

7. Juice extraction $(\%): 34.4$

8. Brix $(\%): 11$

9. Sugar yield $\left(\mathrm{t} \mathrm{ha}^{-1}\right): 0.6$

10. Grain yield $\left(\mathrm{t} \mathrm{ha}^{-1}\right): 1.4$

11. Male fertility restoration (\%): 75

12. Sucrose (\%): 5.7

13. Glucose (\%): 1.2

14. Fructose (\%): 0.7

15. $\mathrm{pH}$ of juice: 5.1

16. Electrical conductivity of juice $\left(\mathrm{mS} \mathrm{m}^{-1}\right) *$ milli siemens per meter: 10.2

17. Tolerance to: Stem borer

18. Adaptation: Rainy season 
Traits recorded as per guidelines for sorghum as approved by PPVFRA ${ }^{\text {a }}$

Characteristics

Characteristic value of Remarks

candidate hybrid parent

Measured value

\begin{tabular}{llllllllll}
\hline 1 & 2 & 3 & 4 & 5 & 6 & 7 & 8 & 9 & etc.
\end{tabular}

Seedling: anthocyanin colouration of coleoptile

Leaf sheath: anthocyanin colouration

Leaf: midrib colour (5th fully developed leaf)

Plant: time of panicle emergence $(50 \%$ of the plants with complete panicle emergence)

Plant: natural height of foliage up to base of flag leaf

Flag leaf: yellow colouration of midrib

Lemma: arista formation (awns)

Stigma: anthocyanin coloration

Stigma: yellow coloration

Stigma length (mm)

Flower with pedicel: length of flower

Anther: length

Anther: colour of dry anther

Glume: color

Plant: total height

Stem: diameter (at lower one-third height of plant) (mm)

Leaf: length of blade of the third leaf from top including flag leaf $(\mathrm{cm})$

Leaf: width of blade of the third leaf from top including flag leaf $(\mathrm{cm})$

Panicle: length without peduncle

Panicle: length of branches (middle third of panicle)

Panicle: density at maturity (ear head compactness)

Panicle: shape

Neck of panicle: visible length above sheath $(\mathrm{cm})$

Glume coverage $(\%)$

Threshability

Caryopsis: colour after threshing

Grain: weight of 1000 grains (g)

Grain: shape in dorsal view

Grain: shape in profile view

Grain: size of mark of germ

Grain: texture of endosperm (in longitudinal section)

Grain: colour of vitreous albumen

Grain: lustre

Purple

Green

Green

70

1.8

Absent

$\sqrt{ }$ Strong

Absent

Medium

Medium

Medium

Medium

Orange

Red

2.1

14.1

73.1

7.3

21

6

Semi compact

Symmetric

11.4

50

Partly

threshable

White

43.0

Circular

Circular

Large

$75 \%$ corneous

Yellow

Medium

${ }^{a}$ PPVFRA Protection of Plant Varieties and Farmers Rights Act 


\section{ICSB 675 Salient Features}

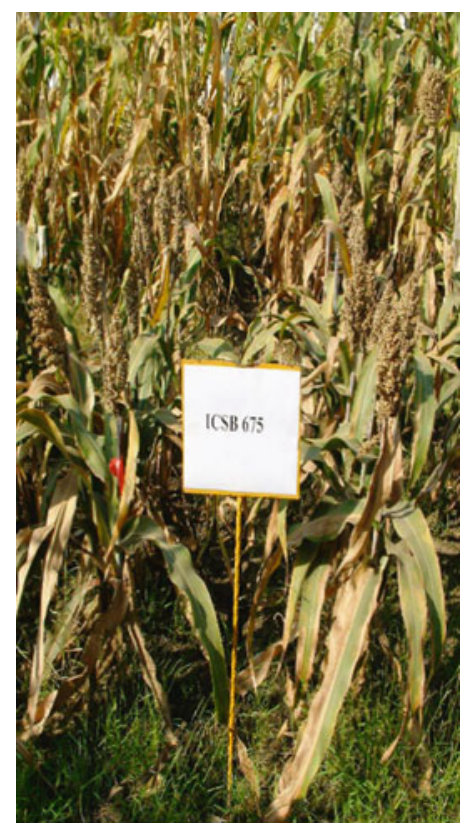

1. Pedigree: $(E$ 36-1 × ICSB 17) $-12-2$

2. Days to $50 \%$ flowering: 76 days.

3. Plant height $(\mathrm{m}): 1.2$

4. Plant girth $(\mathrm{mm}): 15.0$

5. Biomass yield $\left(\mathrm{t} \mathrm{ha}^{-1}\right): 21.4$

6. Juice yield $\left(\mathrm{t} \mathrm{ha}^{-1}\right): 6.7$

7. Juice extraction (\%): 31.3

8. Brix (\%): 12

9. Sugar yield $\left(\mathrm{t} \mathrm{ha}^{-1}\right): 0.6$

10. Grain yield $\left(\mathrm{t} \mathrm{ha}^{-1}\right): 0.6$

11. Male fertility restoration (\%): 60

12. Sucrose $(\%): 1.7$

13. Glucose $(\%): 2.4$

14. Fructose (\%): 0.7

15. $\mathrm{pH}$ of juice 5.3

16. Electrical conductivity of juice $\left(\mathrm{mS} \mathrm{m}^{-1}\right) *$ Milli siemens per meter: 12.2

17. Tolerance to: Aphids, terminal drought.

18. Adaptation: Rainy season 
Traits recorded as per guidelines for sorghum as approved by PPVFRA ${ }^{\text {a }}$

Characteristics

Characteristic value of Remarks

candidate hybrid parent

Measured value

\begin{tabular}{lllllllll}
\hline 1 & 2 & 3 & 4 & 5 & 6 & 7 & 8 & 9
\end{tabular} etc.

Seedling: anthocyanin colouration of coleoptile

Leaf sheath: anthocyanin colouration

Leaf: midrib colour (5th fully developed leaf)

Plant: time of panicle emergence $(50 \%$ of the plants with complete panicle emergence)

Plant: natural height of foliage up to base of flag leaf

Flag leaf: yellow colouration of midrib

Lemma: arista formation (awns)

Stigma: anthocyanin coloration

Stigma: yellow coloration

Stigma length $(\mathrm{mm})$

Flower with pedicel: length of flower

Anther: length

Anther: colour of dry anther

Glume: color

Plant: total height

Stem: diameter (at lower one-third height of plant) (mm)

Leaf: length of blade of the third leaf from top including flag leaf $(\mathrm{cm})$

Leaf: width of blade of the third leaf from top including flag leaf $(\mathrm{cm})$

Panicle: length without peduncle

Panicle: length of branches (middle third of panicle)

Panicle: density at maturity (ear head compactness)

Panicle: shape

Neck of panicle: visible length above sheath (cm)

Glume coverage (\%)

Threshability

Caryopsis: colour after threshing

Grain: weight of 1000 grains (g)

Grain: shape in dorsal view

Grain: shape in profile view

Grain: size of mark of germ

Grain: texture of endosperm (in longitudinal section)

Grain: colour of vitreous albumen

Grain: lustre

Purple

Purple

Brown

76

1.0

Absent

Absent

Absent

Average

Short

Medium

Medium

Orange

Purple

1.2

15.0

85.3

$\sqrt{ } 8.5$

21

7.4

Semi compact

Symmetric

12.7

25

Freely

threshable

White

16.0

Circular

Circular

Large

$75 \%$ corneous

Yellow

Medium

${ }^{a}$ PPVFRA Protection of Plant Varieties and Farmers Rights Act 


\section{ICSB 702 Salient Features}

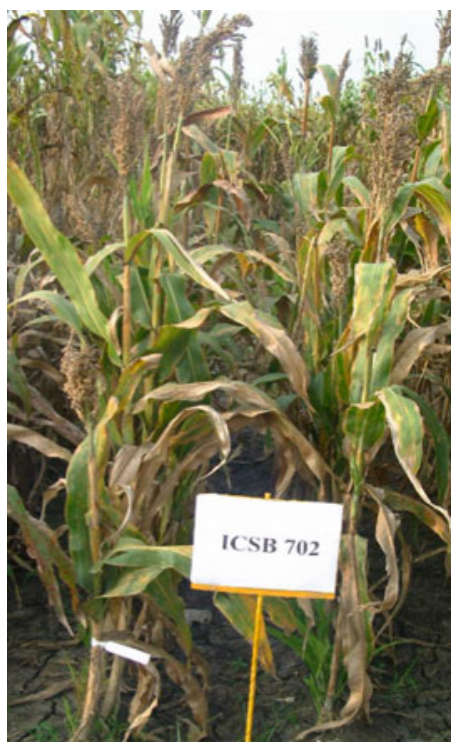

1. Pedigree: (ICSB $101 \times$ SP 36257)-3-3-1-2

2. Days to $50 \%$ flowering: 67 days.

3. Plant height $(\mathrm{m}): 1.6$

4. Plant girth (mm): 15.0

5. Biomass yield $\left(\mathrm{t} \mathrm{ha}^{-1}\right): 17.4$

6. Juice yield $\left(\mathrm{t} \mathrm{ha}^{-1}\right): 7.6$

7. Juice extraction $(\%): 43.6$

8. Brix (\%): 13

9. Sugar yield $\left(\mathrm{t} \mathrm{ha}^{-1}\right): 0.74$

10. Grain yield $\left(\mathrm{t} \mathrm{ha}^{-1}\right): 4.1$

11. Male fertility restoration (\%): 70

12. Sucrose (\%): 4.8

13. Glucose (\%): 1.0

14. Fructose (\%): 0.6

15. $\mathrm{pH}$ of juice: 5.3

16. Electrical conductivity of juice $\left(\mathrm{mS} \mathrm{m}^{-1}\right) *$ Milli siemens per meter: 11.5

17. Tolerance to: Aphids.

18. Adaptation: Rainy season. 
Traits recorded as per guidelines for sorghum as approved by PPVFRA ${ }^{\text {a }}$

Characteristics

Characteristic value of Remarks

candidate hybrid parent

Measured value

$\begin{array}{lllllllll}1 & 2 & 3 & 4 & 5 & 6 & 7 & 8 & 9\end{array}$ etc.

Seedling: anthocyanin colouration of coleoptile

Leaf sheath: anthocyanin colouration

Leaf: midrib colour (5th fully developed leaf)

Plant: time of panicle emergence $(50 \%$ of the plants with complete panicle emergence)

Plant: natural height of foliage up to base of flag leaf

Flag leaf: yellow colouration of midrib

Lemma: arista formation (awns)

Stigma: anthocyanin coloration

Stigma: yellow coloration

Stigma length $(\mathrm{mm})$

Flower with pedicel: length of flower

Anther: length

Anther: colour of dry anther

Glume: color

Plant: total height

Stem: diameter (at lower one-third height of plant) (mm)

Leaf: length of blade of the third leaf from top including flag leaf $(\mathrm{cm})$

Leaf: width of blade of the third leaf from top including flag leaf $(\mathrm{cm})$

Panicle: length without peduncle

Panicle: length of branches (middle third of panicle)

Panicle: density at maturity (ear head compactness)

Panicle: shape

$\sqrt{ }$
$\sqrt{ }$


$\sqrt{ }$
$\sqrt{ }$
$\sqrt{ }$

Green

$\sqrt{ }$

$\begin{array}{ll}\sqrt{ } & \text { Green } \\ & \text { Brown }\end{array}$

67

1.4

Neck of panicle: visible length above sheath (cm)

Glume coverage (\%)

Threshability

Caryopsis: colour after threshing

Grain: weight of 1000 grains (g)

Grain: shape in dorsal view

Grain: shape in profile view

Grain: size of mark of germ

Grain: texture of endosperm (in longitudinal section)

Grain: colour of vitreous albumen

Grain: lustre

Absent

Absent

Absent

Average

$\sqrt{ } \quad$ Short

Short

Short

Orange

Light red

1.6

15.0

80.9

/ 7.8

24.1

7.4

Semi compact

Symmetric

25

Partly

threshable

Light yellow

37.0

Circular

Circular

Large

$75 \%$ corneous

Yellow

Medium

${ }^{a}$ PPVFRA Protection of Plant Varieties and Farmers Rights Act 


\section{ICSB 724 Salient Features}

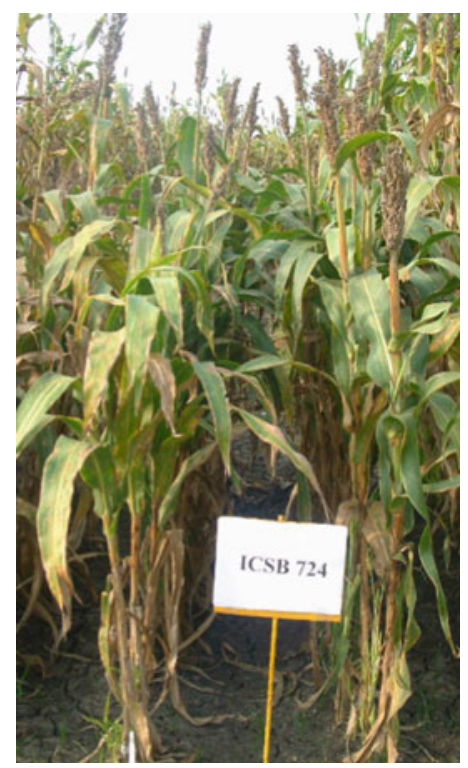

1. Pedigree: ICSP 1B/R MFR-S 7-303-2-1

2. Days to $50 \%$ flowering: 76 days

3. Plant height $(\mathrm{m}): 1.9$

4. Plant girth (mm): 15.0

5. Biomass yield $\left(\mathrm{t} \mathrm{ha}^{-1}\right): 24.8$

6. Juice yield $\left(\mathrm{t} \mathrm{ha}^{-1}\right): 9.7$

7. Juice extraction (\%): 39.1

8. Brix (\%): 13

9. Sugar yield $\left(\mathrm{t} \mathrm{ha}^{-1}\right): 0.9$

10. Grain yield $\left(\mathrm{t} \mathrm{ha}^{-1}\right): 4.3$

11. Male fertility restoration $(\%): 75$

12. Sucrose (\%): 4.6

13. Glucose (\%): 1.4

14. Fructose (\%): 0.4

15. $\mathrm{pH}$ of juice 5.3

16. Electrical conductivity of juice $\left(\mathrm{mS} \mathrm{m}^{-1}\right) *$ Milli siemens per meter: 9.7

17. Tolerance to: Aphids

18. Adaptation: Rainy season. 
Traits recorded as per guidelines for sorghum as approved by PPVFRA ${ }^{\text {a }}$

Characteristics

Characteristic value of Remarks

candidate hybrid parent

Measured value

\begin{tabular}{lllllllll}
\hline 1 & 2 & 3 & 4 & 5 & 6 & 7 & 8 & 9
\end{tabular} etc.

Seedling: anthocyanin colouration of coleoptile

Leaf sheath: anthocyanin colouration

Leaf: midrib colour (5th fully developed leaf)

Plant: time of panicle emergence $(50 \%$ of the plants with complete panicle emergence)

Plant: natural height of foliage up to base of flag leaf

Flag leaf: yellow colouration of midrib

Lemma: arista formation (awns)

Stigma: anthocyanin coloration

Stigma: yellow coloration

Stigma length $(\mathrm{mm})$

Flower with pedicel: length of flower

Anther: length

Anther: colour of dry anther

Glume: color

Plant: total height

Stem: diameter (at lower one-third height of plant) (mm)

Leaf: length of blade of the third leaf from top including flag leaf $(\mathrm{cm})$

Leaf: width of blade of the third leaf from top including flag leaf $(\mathrm{cm})$

Panicle: length without peduncle

Panicle: length of branches (middle third of panicle)

Panicle: density at maturity (ear head compactness)

Panicle: shape

Neck of panicle: visible length above sheath $(\mathrm{cm})$

Glume coverage $(\%)$

Threshability

Caryopsis: colour after threshing

Grain: weight of 1000 grains (g)

Grain: shape in dorsal view

Grain: shape in profile view

Grain: size of mark of germ

Grain: texture of endosperm (in longitudinal section)

Grain: colour of vitreous albumen

Grain: lustre

Purple

Green

Green

76

1.7

Absent

Absent

Absent

Average

Short

Short

Medium

Orange

Light red

1.9

15.0

78.4

$\sqrt{ } 9.1$

20.7

6.5

Semi compact

Symmetric

8.2

25

Partly

threshable

Light yellow

27.0

Circular

Circular

Medium

$25 \%$ corneous

Yellow

Lustrous

${ }^{\text {a }}$ PPVFRA Protection of Plant Varieties and Farmers Rights Act 


\section{ICSB 731 Salient Features}

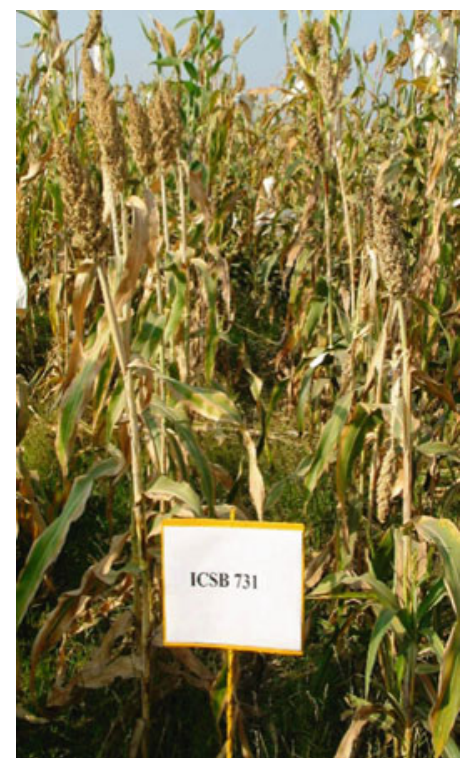

1. Pedigree: ICSV $117 \mathrm{BF}$

2. Days to $50 \%$ flowering: 74 days

3. Plant height $(\mathrm{m}): 2.0$

4. Plant girth (mm): 16.4

5. Biomass yield $\left(\mathrm{t} \mathrm{ha}^{-1}\right): 20.3$

6. Juice yield $\left(\mathrm{t} \mathrm{ha}^{-1}\right): 9.2$

7. Juice extraction (\%): 45

8. Brix (\%): 14

9. Sugar yield $\left(\mathrm{t} \mathrm{ha}^{-1}\right): 1.0$

10. Grain yield $\left(\mathrm{t} \mathrm{ha}^{-1}\right): 3.9$

11. Male fertility restoration (\%): 70

12. Sucrose (\%): 6.9

13. Glucose (\%): 2.9

14. Fructose $(\%): 1.3$

15. $\mathrm{pH}$ of juice: 5.1

16. Electrical conductivity of Juice $\left(\mathrm{mS} \mathrm{m}^{-1}\right) *$ Milli siemens per meter: 9.1

17. Tolerance to: Anthracnose.

18. Adaptation: Rainy season 
Traits recorded as per guidelines for sorghum as approved by PPVFRA ${ }^{\text {a }}$

Characteristics

Characteristic value of Remarks

candidate hybrid parent

Measured value

\begin{tabular}{llllllllll}
\hline 1 & 2 & 3 & 4 & 5 & 6 & 7 & 8 & 9 & etc.
\end{tabular}

Seedling: anthocyanin colouration of coleoptile

Leaf sheath: anthocyanin colouration

Leaf: midrib colour (5th fully developed leaf)

Plant: time of panicle emergence $(50 \%$ of the plants with complete panicle emergence)

Plant: natural height of foliage up to base of flag leaf

Flag leaf: yellow colouration of midrib

Lemma: arista formation (awns)

Stigma: anthocyanin coloration

Stigma: yellow coloration

Stigma length $(\mathrm{mm})$

Flower with pedicel: length of flower

Anther: length

Anther: colour of dry anther

Glume: color

Plant: total height

Stem: diameter (at lower one-third height of plant) (mm)

Leaf: length of blade of the third leaf from top including flag leaf $(\mathrm{cm})$

Leaf: width of blade of the third leaf from top including flag leaf $(\mathrm{cm})$

Panicle: length without peduncle

Panicle: length of branches (middle third of panicle)

Panicle: density at maturity (ear head compactness)

Panicle: shape

Neck of panicle: visible length above sheath $(\mathrm{cm})$

Glume coverage $(\%)$

Threshability

Caryopsis: colour after threshing

Grain: weight of 1000 grains (g)

Grain: shape in dorsal view

Grain: shape in profile view

Grain: size of mark of germ

Grain: texture of endosperm (in longitudinal section)

Grain: colour of vitreous albumen

Grain: lustre

Purple

Green

Brown

74

1.8

Absent

Absent

Absent

Average

Short

Short

Medium

Orange

Light red

2.0

16.4

$\sqrt{ } 88.6$

$\sqrt{ } 8.1$

22.1

6.1

Semi compact

Symmetric

10.8

25

Partly

threshable

White

29.0

Circular

Circular

Medium

$75 \%$ corneous

Yellow

Medium

${ }^{a}$ PPVFRA Protection of Plant Varieties and Farmers Rights Act 


\section{ICSSH 28 Salient Features}

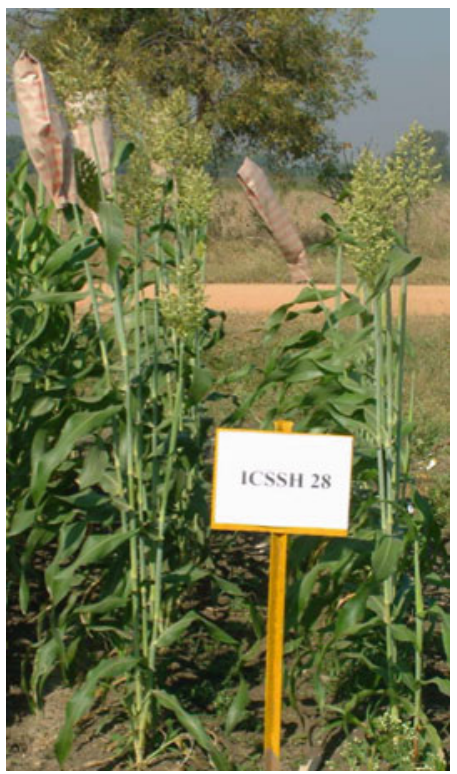

1. Pedigree: ICSA $474 \times$ SSV 74

2. Days to $50 \%$ flowering: 76 days

3. Plant height $(\mathrm{m}): 3.8$

4. Plant girth $(\mathrm{mm}): 17.5$

5. Biomass yield $\left(\mathrm{t} \mathrm{ha}^{-1}\right): 63.6$

6. Juice yield $\left(\mathrm{t} \mathrm{ha}^{-1}\right): 28.3$

7. Juice extraction (\%): 45

8. Brix (\%): 16

9. Sugar yield $\left(\mathrm{t} \mathrm{ha}^{-1}\right): 3.4$

10. Grain yield $\left(\mathrm{t} \mathrm{ha}^{-1}\right): 2.4$

11. Male fertility restoration (\%): 82

12. Sucrose (\%): 6.3

13. Glucose (\%): 1.5

14. Fructose (\%): 0.5

15. $\mathrm{pH}$ of juice 5.0

16. Electrical conductivity of juice $\left(\mathrm{mS} \mathrm{m}^{-1}\right) *$ milli siemens per meter: 9.6

17. Tolerance to: Aphids, Shootfly.

18. Adaptation: Rainy season/post rainy season. 
Traits recorded as per guidelines for sorghum as approved by PPVFRA ${ }^{\text {a }}$

Characteristics

Characteristic value of Remarks

candidate hybrid

Measured value

\begin{tabular}{llllllllll}
\hline 1 & 2 & 3 & 4 & 5 & 6 & 7 & 8 & 9 & etc.
\end{tabular}

Seedling: anthocyanin colouration of coleoptile

Leaf sheath: anthocyanin colouration

Leaf: midrib colour (5th fully developed leaf)

Plant: time of panicle emergence $(50 \%$ of the plants with complete panicle emergence)

Plant: natural height of foliage up to base of flag leaf

Flag leaf: yellow colouration of midrib

Lemma: arista formation (awns)

Stigma: anthocyanin coloration

Stigma: yellow coloration

Stigma length (mm)

Flower with pedicel: length of flower

Anther: length

Anther: colour of dry anther

Glume: color

Plant: total height

Stem: diameter (at lower one-third height of plant) (mm)

Leaf: length of blade of the third leaf from top including flag leaf $(\mathrm{cm})$

Leaf: width of blade of the third leaf from top including flag leaf $(\mathrm{cm})$

Panicle: length without peduncle

Panicle: length of branches (middle third of panicle)

Panicle: density at maturity (ear head compactness)

Panicle: shape

Neck of panicle: visible length above sheath $(\mathrm{cm})$

Glume coverage $(\%)$

Threshability

Caryopsis: colour after threshing

Grain: weight of 1000 grains (g)

Grain: shape in dorsal view

Grain: shape in profile view

Grain: size of mark of germ

Grain: texture of endosperm (in longitudinal section)

Grain: colour of vitreous albumen

Grain: lustre

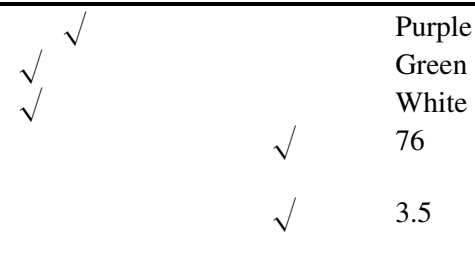

Purple

Green

White

3.5

$\sqrt{ }$
$\sqrt{ }$
$\sqrt{ }$

Absent

Absent

Absent

Medium

Short

Long

Medium

Orange

Red

3.8

17.5

$\sqrt{ } 81.1$

$\sqrt{ } 9.8$

24.2

7.9

Semi loose

Symmetric

11.7

25

Freely

threshable

White

$\sqrt{ } 47.0$

Circular

Circular

Large

$75 \%$ corneous

Yellow

Non-Lustrous

${ }^{a}$ PPVFRA Protection of Plant Varieties and Farmers Rights Act 
18 ICSSH 29 Salient Features

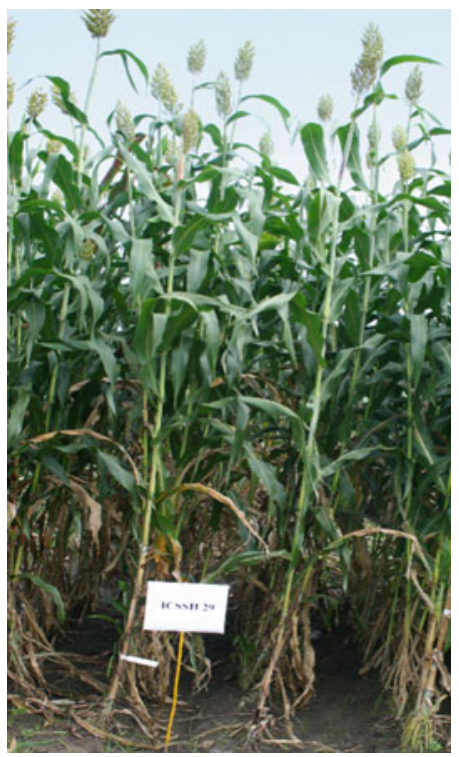

1. Pedigree: ICSA $675 \times$ SSV 74

2. Days to $50 \%$ flowering: 82 days

3. Plant height $(\mathrm{m}): 3.8$

4. Plant girth (mm): 17.8

5. Biomass yield $\left(\mathrm{t} \mathrm{ha}^{-1}\right): 58.5$

6. Juice yield $\left(\mathrm{t} \mathrm{ha}^{-1}\right): 25.4$

7. Juice extraction (\%): 43

8. Brix (\%): 16

9. Sugar yield $\left(\mathrm{t} \mathrm{ha}^{-1}\right): 3.6$

10. Grain yield $\left(\mathrm{t} \mathrm{ha}^{-1}\right): 2.8$

11. Male fertility restoration (\%): 82

12. Sucrose (\%): 7.6

13. Glucose (\%): 0.4

14. Fructose (\%): 1.5

15. $\mathrm{pH}$ of juice $: 5.0$

16. Electrical conductivity of juice $\left(\mathrm{mS} \mathrm{m}^{-1}\right) *$ milli siemens per meter: 7.5

17. Tolerance to: Anthracnose.

18. Adaptation: Rainy season 
Traits recorded as per guidelines for sorghum as approved by PPVFRA ${ }^{\text {a }}$

Characteristics

Characteristic value of Remarks

candidate hybrid

measured value

\begin{tabular}{lllllllll}
\hline 1 & 2 & 3 & 4 & 5 & 6 & 7 & 8 & 9
\end{tabular} etc.

Seedling: anthocyanin colouration of coleoptile

Leaf sheath: anthocyanin colouration

Leaf: midrib colour (5th fully developed leaf)

Plant: time of panicle emergence $(50 \%$ of the plants with complete panicle emergence)

Plant: natural height of foliage up to base of flag leaf

Flag leaf: yellow colouration of midrib

Lemma: arista formation (awns)

Stigma: anthocyanin coloration

Stigma: yellow coloration

Stigma length $(\mathrm{mm})$

Flower with pedicel: length of flower

Anther: length

Anther: colour of dry anther

Glume: color

Plant: total height

Stem: diameter (at lower one-third height of plant) (mm)

Leaf: length of blade of the third leaf from top including flag leaf $(\mathrm{cm})$

Leaf: width of blade of the third leaf from top including flag leaf $(\mathrm{cm})$

Panicle: length without peduncle

Panicle: length of branches (middle third of panicle)

Panicle: density at maturity (ear head compactness)

Panicle: shape

Neck of panicle: visible length above sheath $(\mathrm{cm})$

Glume coverage $(\%)$

Threshability

Caryopsis: colour after threshing

Grain: weight of 1000 grains (g)

Grain: shape in dorsal view

Grain: shape in profile view

Grain: size of mark of germ

Grain: texture of endosperm (in longitudinal section)

Grain: colour of vitreous albumen

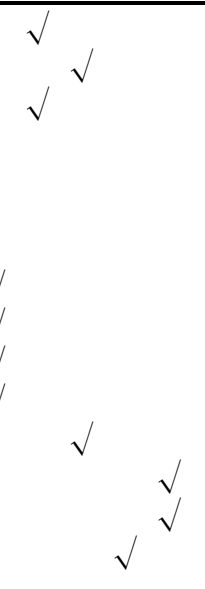

Purple

Purple

Green

82

$\sqrt{ } 3.5$

Absent

Absent

Absent

Absent

Short

Medium

Medium

Orange

$\sqrt{ } \quad$ Purple

$\sqrt{ } \quad 3.8$

$\sqrt{ } \quad 17.8$

$\sqrt{ } 91.4$

$\sqrt{ } 9.9$

25.8

7.4

Semi compact

Symmetric

9.3

25

Partly

threshable

Light yellow

27.0

Circular

Circular

Large

$75 \%$ corneous

Yellow

Grain: lustre

Non-lustrous

${ }^{a}$ PPVFRA Protection of Plant Varieties and Farmers Rights Act 


\section{ICSSH 30 Salient Features}

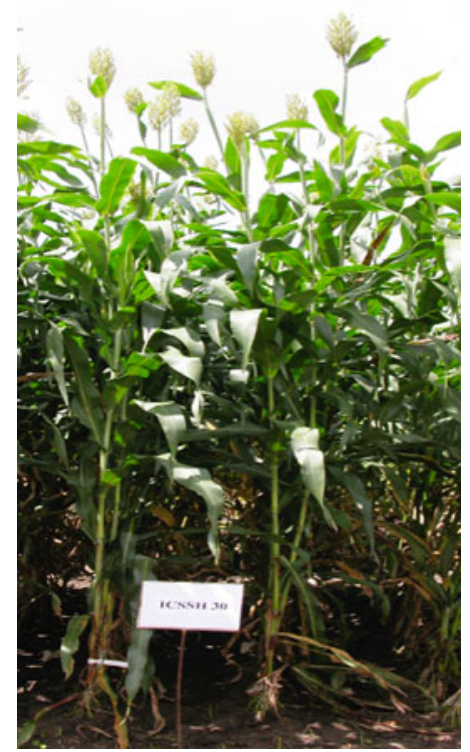

1. Pedigree: ICSA $724 \times$ SSV 74

2. Days to $50 \%$ flowering: 77 days

3. Plant height $(\mathrm{m}): 3.5$

4. Plant girth $(\mathrm{mm}): 18.8$

5. Biomass yield $\left(\mathrm{t} \mathrm{ha}^{-1}\right): 52.0$

6. Juice yield $\left(\mathrm{t} \mathrm{ha}^{-1}\right): 24.5$

7. Juice extraction (\%): 47

8. Brix (\%): 18

9. Sugar yield $\left(\mathrm{t} \mathrm{ha}^{-1}\right): 3.3$

10. Grain yield $\left(\mathrm{t} \mathrm{ha}^{-1}\right): 2.2$

11. Male fertility restoration (\%): 92

12. Sucrose (\%): 7.8

13. Glucose (\%): 0.6

14. Fructose (\%): 2.0

15. $\mathrm{pH}$ of juice: 5.0

16. Electrical conductivity of juice $\left(\mathrm{mS} \mathrm{m}^{-1}\right) *$ Milli siemens per meter: 7.5

17. Tolerance to: Anthracnose, Rust.

18. Adaptation: Rainy season 
Traits recorded as per guidelines for sorghum as approved by PPVFRA ${ }^{\text {a }}$

Characteristics

Characteristic value of Remarks candidate hybrid

measured value

$\begin{array}{lllllllll}1 & 2 & 3 & 4 & 5 & 6 & 7 & 8 & 9\end{array}$ etc.

Seedling: anthocyanin colouration of coleoptile

Leaf sheath: anthocyanin colouration

Leaf: midrib colour (5th fully developed leaf)

Plant: time of panicle emergence $(50 \%$ of the plants with complete panicle emergence)

Plant: natural height of foliage up to base of flag leaf

Flag leaf: yellow colouration of midrib

Lemma: arista formation (awns)

Stigma: anthocyanin coloration

Stigma: yellow coloration

Stigma length (mm)

Flower with pedicel: length of flower

Anther: length

Anther: colour of dry anther

Glume: color

Plant: total height

Stem: diameter (at lower one-third height of plant) (mm)

Leaf: length of blade of the third leaf from top including flag leaf $(\mathrm{cm})$

Leaf: width of blade of the third leaf from top including flag leaf $(\mathrm{cm})$

Panicle: length without peduncle

Panicle: length of branches (middle third of panicle)

Panicle: density at maturity (ear head compactness)

Panicle: shape

Neck of panicle: visible length above sheath (cm)

Glume coverage (\%)

Threshability

Caryopsis: colour after threshing

Grain: weight of 1000 grains (g)

Grain: shape in dorsal view

Grain: shape in profile view

Grain: size of mark of germ

Grain: texture of endosperm (in longitudinal section)

Grain: colour of vitreous albumen

Grain: lustre

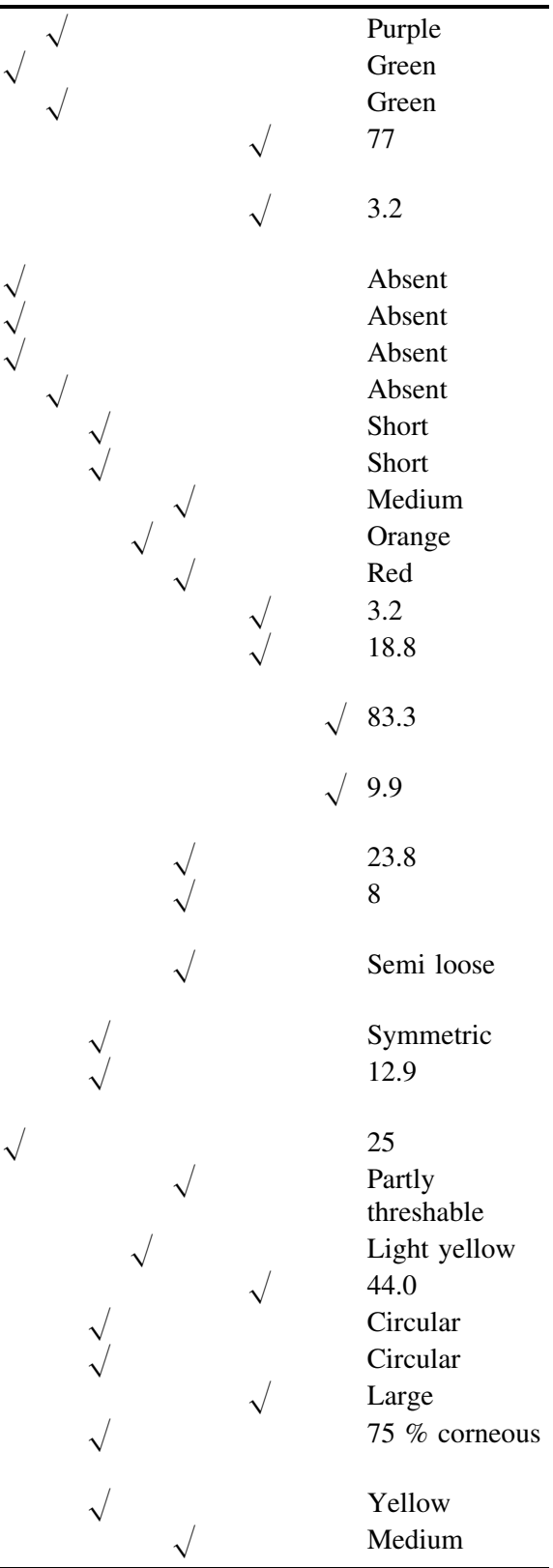

${ }^{a}$ PPVFRA Protection of Plant Varieties and Farmers Rights Act 


\section{ICSSH 31 Salient Features}

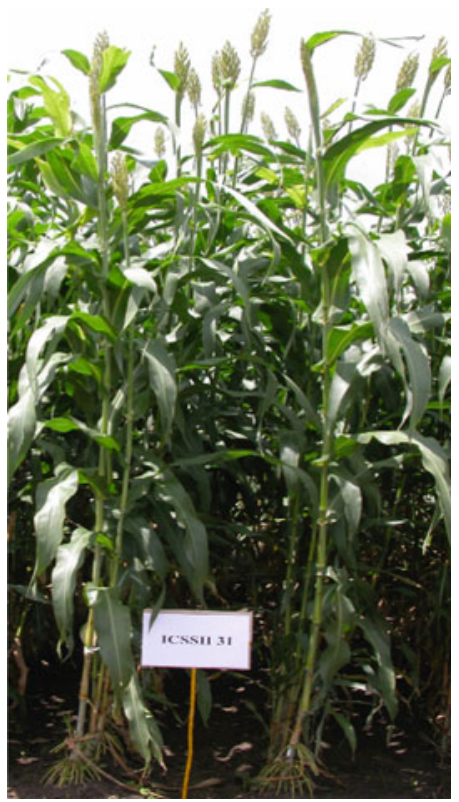

1. Pedigree: ICSA $38 \times$ ICSV 700

2. Days to $50 \%$ flowering: 75 days.

3. Plant height $(\mathrm{m}): 3.1$

4. Plant girth $(\mathrm{mm}): 14.2$

5. Biomass yield $\left(\mathrm{t} \mathrm{ha}^{-1}\right): 51.2$

6. Juice yield $\left(\mathrm{t} \mathrm{ha}^{-1}\right): 22.4$

7. Juice extraction (\%): 44

8. Brix (\%): 16

9. Sugar yield $\left(\mathrm{t} \mathrm{ha}^{-1}\right): 2.7$

10. Grain yield $\left(\mathrm{tha}^{-1}\right): 3.3$

11. Male fertility restoration (\%): 91

12. Sucrose (\%): 8.4

13. Glucose (\%): 0.2

14. Fructose (\%): 1.4

15. $\mathrm{pH}$ of juice: 5.0

16. Electrical conductivity of juice $\left(\mathrm{mS} \mathrm{m}^{-1}\right) *$ milli siemens per meter: 9.3

17. Tolerance to: Aphids, Anthracnose, Shootfly, Rust

18. Adaptation: Rainy season 
Traits recorded as per guidelines for sorghum as approved by PPVFRA ${ }^{\text {a }}$

Characteristics

Characteristic value of Remarks

candidate hybrid

measured value

\begin{tabular}{llllllllll}
\hline 1 & 2 & 3 & 4 & 5 & 6 & 7 & 8 & 9 & etc.
\end{tabular}

Seedling: anthocyanin colouration of coleoptile

Leaf sheath: anthocyanin colouration

Leaf: midrib colour (5th fully developed leaf)

Plant: time of panicle emergence $(50 \%$ of the plants with complete panicle emergence)

Plant: natural height of foliage up to base of flag leaf

Flag leaf: yellow colouration of midrib

Lemma: arista formation (awns)

Stigma: anthocyanin coloration

Stigma: yellow coloration

Stigma length $(\mathrm{mm})$

Flower with pedicel: length of flower

Anther: length

Anther: colour of dry anther

Glume: color

Plant: total height

Stem: diameter (at lower one-third height of plant) (mm)

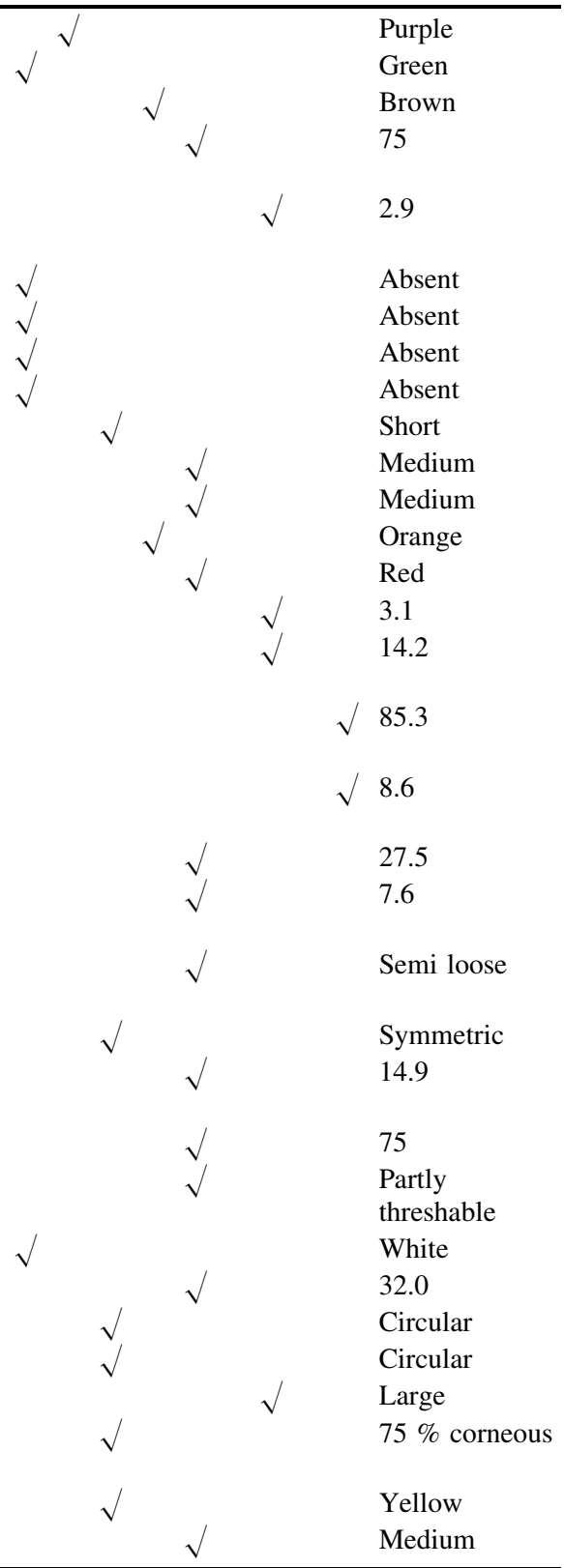

Leaf: length of blade of the third leaf from top including flag leaf $(\mathrm{cm})$

Leaf: width of blade of the third leaf from top including flag leaf $(\mathrm{cm})$

Panicle: length without peduncle

Panicle: length of branches (middle third of panicle)

Panicle: density at maturity (ear head compactness)

Panicle: shape

Neck of panicle: visible length above sheath $(\mathrm{cm})$

Glume coverage (\%)

Threshability

Caryopsis: colour after threshing

Grain: weight of 1000 grains (g)

Grain: shape in dorsal view

Grain: shape in profile view

Grain: size of mark of germ

Grain: texture of endosperm (in longitudinal section)

Grain: colour of vitreous albumen

Grain: lustre

Medium

${ }^{a}$ PPVFRA Protection of Plant Varieties and Farmers Rights Act 


\section{ICSSH 39 Salient Features}

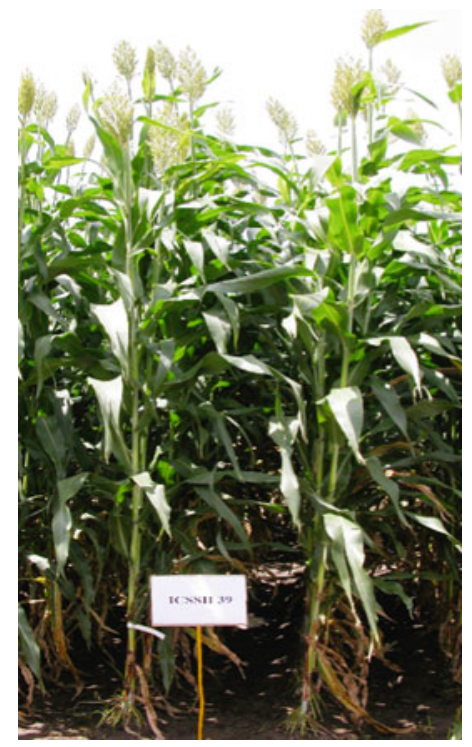

1. Pedigree: ICSA $702 \times$ SSV 74

2. Days to $50 \%$ flowering: 74 days.

3. Plant height $(\mathrm{m}): 3.3$

4. Plant girth (mm): 16.4

5. Biomass yield $\left(\mathrm{t} \mathrm{ha}^{-1}\right): 46.9$

6. Juice yield $\left(\mathrm{t} \mathrm{ha}^{-1}\right): 22.5$

7. Juice extraction (\%): 48

8. Brix (\%): 18

9. Sugar yield $\left(\mathrm{t} \mathrm{ha}^{-1}\right): 3.0$

10. Grain yield $\left(\mathrm{t} \mathrm{ha}^{-1}\right): 2.2$

11. Male fertility restoration (\%): 83

12. Sucrose (\%): 8.1

13. Glucose (\%): 1.1

14. Fructose (\%): 0.4

15. $\mathrm{pH}$ of juice: 5.0

16. Electrical conductivity of juice $\left(\mathrm{mS} \mathrm{m}^{-1}\right) *$ milli siemens per meter: 9.5

17. Tolerance to: Aphids, Anthracnose, Rust

18. Adaptation: Rainy season 
Traits recorded as per guidelines for sorghum as approved by PPVFRA*

Characteristics

Characteristic value of Remarks candidate hybrid

measured value $\begin{array}{lllllllll}1 & 2 & 3 & 4 & 5 & 6 & 7 & 8 & 9\end{array}$ etc.

Seedling: anthocyanin colouration of coleoptile

Leaf sheath: anthocyanin colouration

Leaf: midrib colour (5th fully developed leaf)

Plant: time of panicle emergence $(50 \%$ of the plants with complete panicle emergence)

Plant: natural height of foliage up to base of flag leaf

Flag leaf: yellow colouration of midrib

Lemma: arista formation (awns)

Stigma: anthocyanin coloration

Stigma: yellow coloration

Stigma length $(\mathrm{mm})$

Flower with pedicel: length of flower

Anther: length

Anther: colour of dry anther

Glume: color

Plant: total height

Stem: diameter (at lower one-third height of plant) (mm)

Leaf: length of blade of the third leaf from top including flag leaf $(\mathrm{cm})$

Leaf: width of blade of the third leaf from top including flag leaf $(\mathrm{cm})$

Panicle: length without peduncle

Panicle: length of branches (middle third of panicle)

Panicle: density at maturity (ear head compactness)

Panicle: shape

Neck of panicle: visible length above sheath $(\mathrm{cm})$

Glume coverage $(\%)$

Threshability

$\sqrt{ }$
$\sqrt{ }$



$\sqrt{ }$
$\sqrt{ }$
$\sqrt{ }$
$\sqrt{ }$

Green
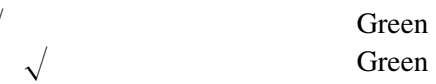

74

3.0

Absent

Absent

Absent

Absent

Medium

Medium

Medium

Orange

Red

3.3

$\sqrt{ } \quad 16.4$

$\sqrt{ } 86.4$

$\sqrt{ } 9.5$

25.8

9.1

Semi loose

Symmetric

9.3

25

Freely

threshable

Caryopsis: colour after threshing

Grain: weight of 1000 grains (g)

Grain: shape in dorsal view

Grain: shape in profile view

Grain: size of mark of germ

Grain: texture of endosperm (in longitudinal section)

Grain: colour of vitreous albumen

Grain: lustre

Light yellow

36.0

Circular

Circular

Large

$75 \%$ corneous

Yellow

Medium

${ }^{a}$ PPVFRA Protection of Plant Varieties and Farmers Rights Act 


\section{ICSSH 58 Salient Features}

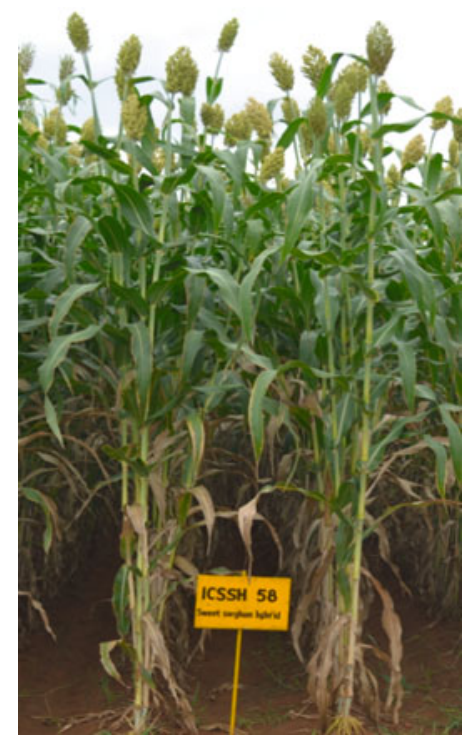

1. Pedigree: ICSA $731 \times$ ICSA 93046 (First A2 cms system based hybrid)

2. Days to $50 \%$ flowering: 79 days.

3. Plant height $(\mathrm{m}): 3.4$

4. Plant girth $(\mathrm{mm}): 15.0$

5. Biomass yield $\left(\mathrm{t} \mathrm{ha}^{-1}\right): 57.5$

6. Juice yield $\left(\mathrm{t} \mathrm{ha}^{-1}\right): 29.4$

7. Juice extraction (\%): 51

8. Brix (\%): 17

9. Sugar yield $\left(\mathrm{t} \mathrm{ha}^{-1}\right): 3.8$

10. Grain yield $\left(\mathrm{t} \mathrm{ha}^{-1}\right): 2.9$

11. Male fertility restoration (\%): 93

12. Sucrose (\%): 9.9

13. Glucose $(\%): 0.3$

14. Fructose (\%): 1.2

15. $\mathrm{pH}$ of juice: 5.0

16. Electrical conductivity of juice $\left(\mathrm{mS} \mathrm{m}^{-1}\right) *$ milli siemens per meter: 9.6

17. Tolerance to: Aphids, Shootfly, Anthracnose.

18. Adaptation: Rainy season 
Traits recorded as per guidelines for sorghum as approved by PPVFRA ${ }^{\text {a }}$

\begin{tabular}{ll}
\hline Characteristics & $\begin{array}{l}\text { Characteristic value of } \\
\text { candidate hybrid }\end{array}$
\end{tabular}

Remarks candidate hybrid measured value \begin{tabular}{llllllllll}
\hline 1 & 2 & 3 & 4 & 5 & 6 & 7 & 8 & 9 & etc.
\end{tabular}

Seedling: anthocyanin colouration of coleoptile Leaf sheath: anthocyanin colouration

Leaf: midrib colour (5th fully developed leaf)

Plant: time of panicle emergence $(50 \%$ of the plants with complete panicle emergence)

Plant: natural height of foliage up to base of flag leaf

Flag leaf: yellow colouration of midrib

Lemma: arista formation (awns)

Stigma: anthocyanin coloration

Stigma: yellow coloration

Stigma length $(\mathrm{mm})$

Flower with pedicel: length of flower

Anther: length

Anther: colour of dry anther

Glume: color

Plant: total height

Stem: diameter (at lower one-third height of plant) (mm)

Leaf: length of blade of the third leaf from top including flag leaf $(\mathrm{cm})$

Leaf: width of blade of the third leaf from top including flag leaf $(\mathrm{cm})$

Panicle: length without peduncle

Panicle: length of branches (middle third of panicle)

Panicle: density at maturity (ear head compactness)

Panicle: shape

Neck of panicle: visible length above sheath $(\mathrm{cm})$

Glume coverage $(\%)$

Threshability

Caryopsis: colour after threshing

Grain: weight of 1000 grains (g)

Grain: shape in dorsal view

Grain: shape in profile view

Grain: size of mark of germ

Grain: texture of endosperm (in longitudinal section)

Grain: colour of vitreous albumen

Grain: lustre

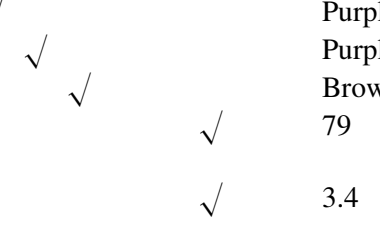

Absent

Absent

Absent

Absent

Short

Medium

Medium

Orange

Red

3.7

15.0

85.9

$\sqrt{ } 9.3$

20.7

6.7

Semi compact

Symmetric

8.3

50

Partly

threshable

White

25.0

Circular

Circular

Medium

$25 \%$ corneous

Yellow

Medium

${ }^{a}$ PPVFRA Protection of Plant Varieties and Farmers Rights Act 


\section{ICSSH 25 Salient Features}

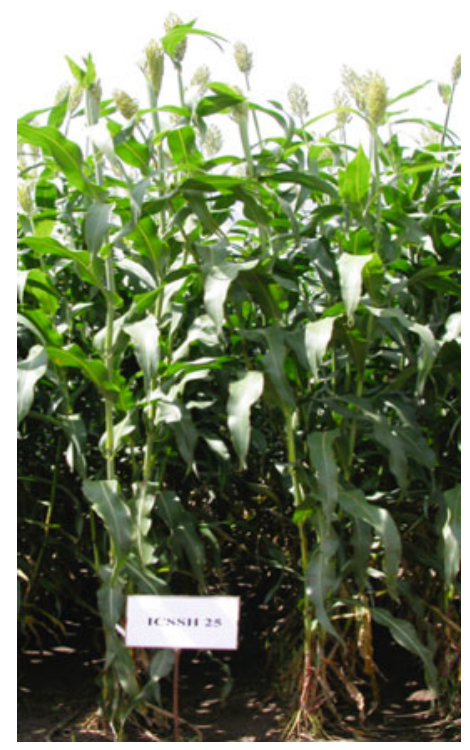

1. Pedigree: ICSA $675 \times$ ICSV 700

2. Days to $50 \%$ flowering: 77 days.

3. Plant height $(\mathrm{m}): 3.5$

4. Plant girth $(\mathrm{mm}): 18.1$

5. Biomass yield $\left(\mathrm{t} \mathrm{ha}^{-1}\right): 54.8$

6. Juice yield $\left(\mathrm{t} \mathrm{ha}^{-1}\right): 28.5$

7. Juice extraction (\%): 52

8. Brix (\%): 17

9. Sugar yield $\left(\mathrm{t} \mathrm{ha}^{-1}\right): 3.6$

10. Grain yield $\left(\mathrm{t} \mathrm{ha}^{-1}\right): 3.1$

11. Male fertility restoration (\%): 86

12. Sucrose (\%): 6.3

13. Glucose (\%): 1.3

14. Fructose (\%): 0.3

15. $\mathrm{pH}$ of juice: 5.0

16. Electrical conductivity of juice $\left(\mathrm{mS} \mathrm{m}^{-1}\right) *$ milli siemens per meter: 10.3

17. Tolerance to: Aphids, Rust.

18. Adaptation: Rainy season. 
Traits recorded as per guidelines for sorghum as approved by PPVFRA ${ }^{\mathbf{a}}$

Characteristics

Characteristic value of

Remarks

candidate hybrid

measured value

\begin{tabular}{lllllllll}
\hline 1 & 2 & 3 & 4 & 5 & 6 & 7 & 8 & 9
\end{tabular} etc.

Seedling: anthocyanin colouration of coleoptile

Leaf sheath: anthocyanin colouration

Leaf: midrib colour (5th fully developed leaf)

Plant: time of panicle emergence $(50 \%$ of the plants with complete panicle emergence)

Plant: natural height of foliage up to base of flag leaf

Flag leaf: yellow colouration of midrib

Lemma: arista formation (awns)

Stigma: anthocyanin coloration

Stigma: yellow coloration

Stigma length $(\mathrm{mm})$

Flower with pedicel: length of flower

Anther: length

Anther: colour of dry anther

Glume: color

Plant: total height

Stem: diameter (at lower one-third height of plant) (mm)

Leaf: length of blade of the third leaf from top including flag leaf $(\mathrm{cm})$

Leaf: width of blade of the third leaf from top including flag leaf $(\mathrm{cm})$

Panicle: length without peduncle

Panicle: length of branches (middle third of panicle)

Panicle: density at maturity (ear head

compactness)

Panicle: shape

Neck of panicle: visible length above sheath $(\mathrm{cm})$

Glume coverage $(\%)$

Threshability

Caryopsis: colour after threshing

Grain: weight of 1000 grains (g)

Grain: shape in dorsal view

Grain: shape in profile view

Grain: size of mark of germ

Grain: texture of endosperm (in longitudinal section)

Grain: colour of vitreous albumen

Grain: lustre

Purple

Purple

Brown

77

3.2

Absent

Absent

Absent

Absent

Medium

Medium

Medium

Orange

Red

3.5

18.1

76.7

$\sqrt{ } 9.1$

22.9

7.8

Semi loose

Symmetric

7.6

25

Partly

threshable

White

28.0

Circular

Circular

Large

$25 \%$ corneous

Yellow

Lustrous

${ }^{a}$ PPVFRA Protection of Plant Varieties and Farmers Rights Act 


\section{CSH 22 SS Salient Features}

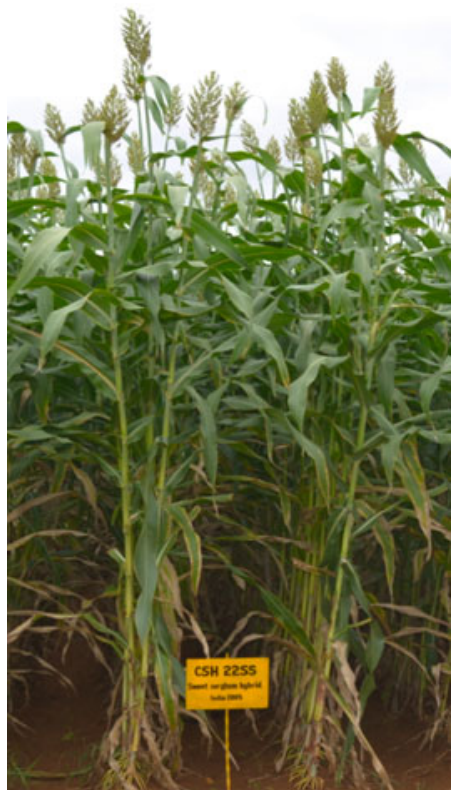

1. Pedigree: ICSA $38 \times$ SSV 84 (Developed by Directorate of Sorghum Research)

2. Days to $50 \%$ flowering: 84 days.

3. Plant height $(\mathrm{m}): 3.3$

4. Plant girth $(\mathrm{mm}): 18.5$

5. Biomass yield $\left(\mathrm{t} \mathrm{ha}^{-1}\right): 51.0$

6. Juice yield $\left(\mathrm{t} \mathrm{ha}^{-1}\right): 22.8$

7. Juice extraction (\%): 44.3

8. Brix (\%): 17

9. Sugar yield $\left(\mathrm{t} \mathrm{ha}^{-1}\right): 2.9$

10. Grain yield $\left(\mathrm{t} \mathrm{ha}^{-1}\right): 2.7$

11. Male fertility restoration (\%): 86

12. Sucrose $(\%): 8.5$

13. Glucose $(\%): 0.3$

14. Fructose $(\%): 1.6$

15. $\mathrm{pH}$ of juice 5.0

16. Electrical conductivity of juice $\left(\mathrm{mS} \mathrm{m}^{-1}\right) *$ milli siemens per meter: 8.9

17. Tolerance to: Aphids, Shoot fly.

18. Adaptation: Rainy season/Post rainy season. 
Traits recorded as per guidelines for sorghum as approved by PPVFRA ${ }^{\text {a }}$

Characteristics

Characteristic value of

Remarks

candidate hybrid

measured value

\begin{tabular}{lllllllll}
\hline 1 & 2 & 3 & 4 & 5 & 6 & 7 & 8 & 9
\end{tabular} etc.

Seedling: anthocyanin colouration of coleoptile

Leaf sheath: anthocyanin colouration

Leaf: midrib colour (5th fully developed leaf)

Plant: time of panicle emergence $(50 \%$ of the plants with complete panicle emergence)

Plant: natural height of foliage up to base of flag leaf

Flag leaf: yellow colouration of midrib

Lemma: arista formation (awns)

Stigma: anthocyanin coloration

Stigma: yellow coloration

Stigma length $(\mathrm{mm})$

Flower with pedicel: length of flower

Anther: length

Anther: colour of dry anther

Glume: color

Plant: total height

Stem: diameter (at lower one-third height of plant) (mm)

Leaf: length of blade of the third leaf from top including flag leaf $(\mathrm{cm})$

Leaf: width of blade of the third leaf from top including flag leaf $(\mathrm{cm})$

Panicle: length without peduncle

Panicle: length of branches (middle third of panicle)

Panicle: density at maturity (ear head compactness)

Panicle: shape

Neck of panicle: visible length above sheath $(\mathrm{cm})$

Glume coverage $(\%)$

Threshability

Caryopsis: colour after threshing

Grain: weight of 1000 grains (g)

Grain: shape in dorsal view

Grain: shape in profile view

Grain: size of mark of germ

Grain: texture of endosperm (in longitudinal section)

Grain: colour of vitreous albumen

Grain: lustre

Yellow green

Yellow green

Yellow green

84

3.0

Absent

Absent

Present

Absent

Medium

Short

Short

Grayed orange

Grayed purple

3.3

$\sqrt{ } \quad$ Medium

$\sqrt{ }$ Very long

$\sqrt{ }$ Vey broad

Medium

Medium

Semi compact

Symmetric

Absent or very

short

Short

Partly thresh

able

Grayed orange

30.0

Circular

Elliptic

$\begin{array}{ll}\sqrt{ } & \text { Medium } \\ \sqrt{ } & 25 \% \text { corneous }\end{array}$

Grayed yellow

Lustrous

${ }^{a}$ PPVFRA Protection of Plant Varieties and Farmers Rights Act 